\title{
A Study on the Role of Reaction Modeling in Multi-phase CFD-based Simulations of Chemical Looping Combustion
}

\author{
H. Kruggel-Emden ${ }^{1,2 *}$, F. Stepanek ${ }^{1}$ and A. Munjiza ${ }^{2}$ \\ 1 Department of Chemical Engineering, South Kensington Campus, Imperial College London, SW7 2AZ, London - UK \\ 2 Department of Engineering, Queen Mary, University of London, Mile End Road, El 4NS, London - UK \\ e-mail: kruggel-emden@leat.rub.de - f.stepanek@imperial.ac.uk - a.munjiza@qmul.ac.uk \\ * Corresponding author
}

\begin{abstract}
Résumé - Impact du modèle de réaction sur les simulations CFD de la combustion en boucle chimique - La combustion en boucle chimique (Chemical Looping Combustion) est une technologie de combustion efficace permettant le captage in situ $\mathrm{du} \mathrm{CO}_{2}$ pour des charges gazeuses ou solides. Dans l'optique du développement et de l'extrapolation du procédé, la CFD est un outil de simulation à fort potentiel qui s'appuie notamment sur des modèles cinétiques pour décrire les réactions gaz-solide. Ces modèles décrivant les réactions sont généralement assez simples pour limiter les temps de simulation et sont obtenus à partir d'expérimentations en thermobalance. Il y a encore peu de travaux de modélisation CFD du procédé CLC et il est difficile d'estimer l'importance du modèle décrivant les réactions chimiques sur les résultats des simulations.

Le but de ce travail est donc d'étudier la combustion de charges gazeuses $\mathrm{H}_{2}$ et $\mathrm{CH}_{4}$ dans des réacteurs en batch en considérant 3 matériaux transporteurs d'oxygène $\left(\mathrm{CaSO}_{4}, \mathrm{Mn}_{3} \mathrm{O}_{4}\right.$ et $\left.\mathrm{NiO}\right)$. Quatre modèles cinétiques (le modèle à cœur rétrécissant linéaire, le modèle à cœur rétrécissant sphérique, le modèle d'Avrami-Erofeev et un modèle plus récent multi-paramètres) ont été utilisés et comparés au cas par cas.
\end{abstract}

\begin{abstract}
A Study on the Role of Reaction Modeling in Multi-phase CFD-based Simulations of Chemical Looping Combustion - Chemical Looping Combustion is an energy efficient combustion technology for the inherent separation of carbon dioxide for both gaseous and solid fuels. For scale up and further development of this process multi-phase CFD-based simulations have a strong potential which rely on kinetic models for the solid/gaseous reactions. Reaction models are usually simple in structure in order to keep the computational cost low. They are commonly derived from thermogravimetric experiments. With only few CFD-based simulations performed on chemical looping combustion, there is a lack in understanding of the role and of the sensitivity of the applied chemical reaction model on the outcome of a simulation.

The aim of this investigation is therefore the study of three different carrier materials $\mathrm{CaSO}_{4}, \mathrm{Mn}_{3} \mathrm{O}_{4}$ and $\mathrm{NiO}$ with the gaseous fuels $\mathrm{H}_{2}$ and $\mathrm{CH}_{4}$ in a batch type reaction vessel. Four reaction models namely the linear shrinking core, the spherical shrinking core, the Avrami-Erofeev and a recently proposed multi parameter model are applied and compared on a case by case basis.
\end{abstract}




\section{NOTATION}

\begin{tabular}{|c|c|c|}
\hline Variable & Unit & Denotation \\
\hline$A_{\mathrm{RZ}}$ & $\left(\mathrm{m}^{2}\right)$ & Area of the reaction zone \\
\hline$a_{n}, a_{m}$ & $(1 / s)$ & Multi parameter model coefficients \\
\hline$b$ & $(-)$ & Stoichiometric constant \\
\hline \multicolumn{2}{|c|}{$b_{n}, c_{n}, d_{m}, b_{m}, c_{m}(-)$} & Multi parameter model coefficients \\
\hline C & $\left(\mathrm{mol} / \mathrm{m}^{3}\right)$ & Concentration \\
\hline$d_{p}$ & $(\mu \mathrm{m})$ & Particle diameter \\
\hline$E$ & $(\mathrm{~kJ} / \mathrm{mol})$ & Reaction activation energy \\
\hline$e$ & $(-)$ & Restitution coefficient \\
\hline$k$ & $(\mathrm{~m} / \mathrm{s})$ & Chemical reaction rate constant \\
\hline$k_{0}$ & $(\mathrm{~m} / \mathrm{s})$ & Chemical reaction rate factor \\
\hline$k$ & $(1 / s)$ & Chemical reaction rate constant \\
\hline$k^{\prime}$, & $\left(\mathrm{m}^{3 n} /\left(\mathrm{mol}^{n} \cdot \mathrm{s}\right)\right.$ & Chemical reaction rate constant \\
\hline$m$ & $(-)$ & Exponent \\
\hline$n$ & $(-)$ & Apparent reaction order \\
\hline$n, m, l$ & $(-)$ & Index \\
\hline$p$ & $(\mathrm{kPa})$ & Pressure \\
\hline$R$ & $(\mathrm{~kJ} /(\mathrm{kmol} \cdot \mathrm{K}))$ & Gas constant \\
\hline$r$ & $\left(\mathrm{~mol} /\left(\mathrm{s} \cdot \mathrm{m}^{3}\right)\right)$ & Reaction rate \\
\hline$r_{c}$ & $(\mu \mathrm{m})$ & $\begin{array}{l}\text { Radial position of the reaction } \\
\text { front }\end{array}$ \\
\hline$r_{h e}$ & $\left(\mathrm{~mol} /\left(\mathrm{s} \cdot \mathrm{m}^{3}\right)\right)$ & Heterogeneous reaction rate \\
\hline$r_{p}$ & $(\mu \mathrm{m})$ & Particle radius \\
\hline$S$ & $(1 / \mu \mathrm{m})$ & Surface area \\
\hline$T$ & $(\mathrm{~K})$ & Temperature \\
\hline$t$ & (s) & Time \\
\hline$v$ & $(\mathrm{~m} / \mathrm{s})$ & Velocity \\
\hline$X$ & $(-)$ & $\begin{array}{l}\text { Volumetric dimensionless } \\
\text { degree of conversion }\end{array}$ \\
\hline Y & $(\mathrm{kg} / \mathrm{kg})$ & Mass fraction \\
\hline$Z$ & $(\mathrm{~mol} / \mathrm{mol})$ & Molar fraction \\
\hline
\end{tabular}

\section{Greek letters}

$\begin{array}{lll}\text { Variable } & \text { Unit } & \text { Denotation } \\ \rho_{\mathrm{g}} & \left(\mathrm{kg} / \mathrm{m}^{3}\right) & \text { Gas density } \\ \varepsilon_{\mathrm{g}} & (-) & \text { Gas volume fraction } \\ \varepsilon_{\mathrm{s}} & (-) & \text { Solid volume fraction } \\ \xi & \left({ }^{\circ}\right. & \text { Angle of internal friction }\end{array}$

\section{Subscripts}

$\begin{array}{ll}\text { Variable } & \text { Denotation } \\ 0 & \text { Initial } \\ \text { AE } & \text { Avrami-Erofeev model } \\ \text { LSC } & \text { Linear shrinking core model } \\ \text { max } & \text { Maximal } \\ \text { SSC } & \text { Spherical shrinking core model } \\ \text { ref } & \text { Reference }\end{array}$

\section{INTRODUCTION}

The increase in average annual surface temperature known as global warming is believed to be linked to human activity through the emissions of greenhouse gases into the earth's atmosphere [1]. As the most dominant source emissions of carbon dioxide from power generation and industrial processes can be identified. Many scientific studies come to the result that a reduction of greenhouse gas emissions in the imminent future is essential to constrain the hazardous impact of global warming [1].

A reduction of emissions could be achieved through the shift towards carbon dioxide free or neutral energy sources like biomass, nuclear, solar, water or wind energy. However, some energy sources like water power or biomass suffer from limited availability, others like wind and solar energy lack the continuous availability and nuclear power is environmentally problematic due to the still unresolved problem of long term waste handling. Therefore industrial processes and energy production have to continue to rely on fossil fuels as their main energy source in the near future.

On this background, a significant reduction in carbon dioxide emissions is feasible through methods of carbon capture and following sequestration $[2,3]$. The methods available for carbon capture can be divided in three main groups as pre-combustion, oxy-fuel combustion and post-combustion technologies. Despite ongoing research most of them still result in a drop in process efficiency of $7-12 \%$ points [3, 4]. An alternative poses chemical looping combustion, which was introduced as a more energy efficient combustion approach $[5,6]$ based on the technical concept originally proposed by Lewis and Gilliland [7]. Ishida et al. [8] and Ishida and Jin [9] introduced and shaped the phrase "chemical looping combustion" for the underlying technical concept which is still used today. In chemical looping combustion a metal oxide is used to supply the necessary oxygen instead of using air. Therefore the combustion products are not diluted with nitrogen and excess oxygen, and nearly pure carbon dioxide can be sequestrated. With such an approach the efficiency drop due to carbon capture can be reduced [10,11]. A basic outline of the process is shown in Figure 1.

The process is based on a concept with two interconnected fluidized or moving bed reactors (Fig. 1a) or run in non fluidized batch operation (Fig. Ib). In the first case a solid oxygen carrier is circulated between both reactors and transports the necessary oxygen from the air-reactor to the fuel-reactor. Here the fuel is combusted without the presence of nitrogen. Carbon dioxide and steam are the only resulting combustion products. By condensing the water vapor, a nearly pure stream of carbon dioxide is obtained and ready for sequestration. The process can be realized through the combination of a bubbling fluidized bed operated as the fuel reactor in combination with a high velocity riser operated as air reactor as proposed by Lyngfelt et al. [12]. In cases where the oxidation 


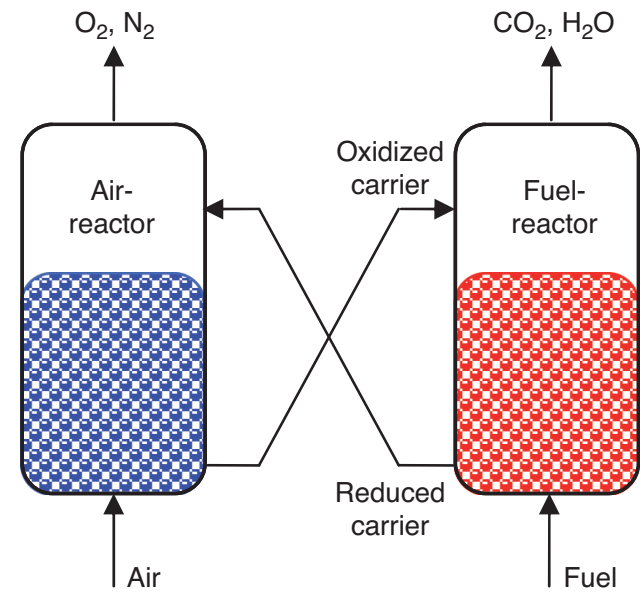

a)

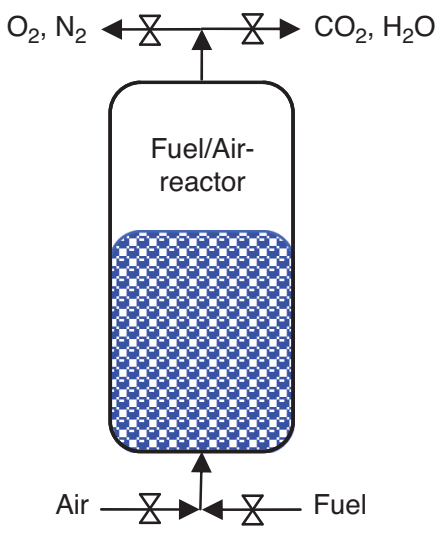

b)

Figure 1

Possible outlines of a chemical looping combustion system: a) interconnected fluidized or moving bed system and b) a packed bed batch system with alternating flow.

reaction in the air reactor is not sufficiently fast a concept involving a double combination of riser and bubbling fluidized bed can be applied as proposed by Son and Kim [13] or moving beds as proposed by Gnanapragasam et al. [14] or Fan et al. [15] can be inherited. Alternatively a batch operation of the chemical looping combustion process is possible as suggested by Noorman et al. [16, 17]. In this case the vessel filled with the oxygen carrier is alternately used as air- and fuel-reactor using a high temperature gas switching system. In order to get a continuous stream of hot gas feedable to a gas turbine at least two reactors have to be operated in parallel. The packed bed concept has the advantage of avoiding any particle/gas separation through a cyclone and is gentler to the particles. However it can not be operated with solid fuels and the design and operation of the hot gas switching system is problematic [16].

For all chemical looping combustion processes suitable oxygen carrier materials have to be provided. Suitable materials should have a high oxidation and reduction activity, remain stable under repeated oxidations/reductions, possess enough mechanical strength, be resilient to agglomeration, be environmental friendly and be of low cost. As materials metal oxides as cobalt, copper, iron, manganese and nickel are deployed. However, materials used for flue gas desulphurization such as calcium sulfide are also applicable [18, 19]. Very often the active metal oxide is supported by an inert carrier material to improve mechanical strength. A comprehensive overview of the important aspects related to the choice and use of certain oxygen carriers can be found in the recent review by Hossaina and de Lasa [20].

With successful operation of laboratory scale chemical looping combustion systems by several research groups with different carrier materials and fuels up to $140 \mathrm{~kW}_{\text {th }}$ [21-26] and the aim to realize even larger systems up to $1 \mathrm{MW}_{\text {th }}[27$, $28,19]$ the demand for applicable modeling strategies in case of chemical looping combustion systems grows. Modeling strategies are essential for the elementary design of chemical looping systems, the sensitivity study of parameters and the scale up of equipment for the use within industrial size processes.

In the following a review of different modeling strategies with special focus on the applied kinetic models is performed. The review of simulations reveals that reaction kinetics is often implemented vaguely especially in case of fluidized systems modeled through the multi-phase CFD-approach. The aim of this study is therefore to investigate the effect of the application of different kinetic models on macroscopic results of typically operated batch fluidized systems. The review of simulation approaches is followed by an outline of the applied simulation framework, an overview over simulation parameters and the simulation results.

\section{MODELING OF CHEMICAL LOOPING COMBUSTION: CURRENT STATE OF RESEARCH}

In general modeling of chemical looping processes can be achieved on different levels of accuracy with very differing computational costs and varying significance of calculated results. It can be distinguished between particle based methods, multi-phase CFD-models and macroscopic continuum approaches. In the given order their computational demand is decreasing. 


\subsection{Particle Based Methods}

For chemical looping combustion no particle based methods have been applied, however, their potential use for reacting particle systems has been outlined in studies on combustion processes in slow moving dense beds by e.g. Simsek et al. [29]. Particle based methods like the discrete element approach allow to model each particle in the system individually representing its temperature, composition, position and velocity. To model the gaseous phase classical CFD-models can be applied which need to be coupled with a discrete phase model [30]. The overall system behavior is given by the interaction of all individual particles along with the surrounding gas phase. Despite their high level of accuracy their applicability is limited to systems of up to $10^{6}$ particles even on modern computer systems. This number is often already exceeded for smaller laboratory scale fluidized beds [20].

\subsection{Multi-phase Fluid Dynamics}

The limitation of considerable particle numbers can be overcome through models based on multi-phase fluid dynamics. These models assume the particle and fluid phase to be modeled in the framework of the Navier-Stokes equations using averaged quantities. Closure equations for the solid phase pressure and the solid phase viscosity have to be provided derived from the kinetic theory of granular flow [31]. The kinetic theory of granular flow is an extension of the classical kinetic gas theory realizing for inelastic particle/particle interaction $[32,33]$. Although these models have been frequently used for bubbling fluidized beds [34], mixing [35], downflow reactors [36] and spouted beds [37], Jung and Gamwo [38] were the first to apply multi-phase CFD modeling for chemical looping combustion processes. In their study the combustion of methane with $\mathrm{NiO}$ as an oxygen carrier was considered. Reduction and oxidation of the carrier are described by the two reactions:

$$
\begin{gathered}
4 \mathrm{NiO}+\mathrm{CH}_{4} \rightarrow \mathrm{CO}_{2}+2 \mathrm{H}_{2} \mathrm{O}+4 \mathrm{Ni} \\
4 \mathrm{Ni}+2 \mathrm{O}_{2} \rightarrow 4 \mathrm{NiO}
\end{gathered}
$$

Jung and Gamwo [38] considered only the oxidation of methane occurring in the fuel reactor which is operated as a bubbling fluidized bed. For the kinetic modeling of this reaction they relied on an shrinking core model as proposed by Ryu et al. [39] which is written in integral form as:

$$
t=\frac{C_{\mathrm{NiO} 0} r_{p}}{b k C_{\mathrm{CH}_{4} 0}}\left[1-(1-X)^{1 / 3}\right]
$$

with the stoichiometric coefficient $b=4, C_{\mathrm{NiO} 0}$ the initial concentration of the solid oxygen carrier material, $C_{\mathrm{CH}_{4} 0}$ the bulk concentration of the gaseous reactant, $r_{p}=80 \mu \mathrm{m}$ the initial particle radius and $X$ the volumetric dimensionless degree of conversion. The chemical reaction rate constant $k$ given in ( $\mathrm{m} / \mathrm{s})$ was derived by Ryu et al. [39] through thermal gravimetrical analysis technique as:

$$
k=k_{0} \exp \left(\frac{E}{R T}\right)
$$

with $E=37070 \mathrm{~kJ} /(\mathrm{kmol})$ and $k_{0}=3.27 \cdot 10^{-2} \mathrm{~m} / \mathrm{s}$.

In their paper Ryu et al. [39] provide an equation to calculate $C_{\mathrm{NiO} 0}$, however, not all necessary data like densities and molar weights are provided rendering it impossible to calculate this value directly. Experiments were performed at three temperatures $T=1023 \mathrm{~K}, T=973 \mathrm{~K}$ and $T=873 \mathrm{~K}$ at a volume fraction of $\mathrm{CH}_{4}$ of $0.0504 \mathrm{~m}^{3} / \mathrm{m}^{3}$ at atmospheric pressure. Based on a best fit for $C_{\mathrm{NiO} 0}$ derived as $2701 \mathrm{~mol} / \mathrm{m}^{3}$ Figure 2 reveals a discrepancy between the calculated degree of conversion of $\mathrm{NiO}$ for the shrinking core model based in Equations $(3,4)$ (solid line) and graphical results (dashed line) published in the original paper [39].

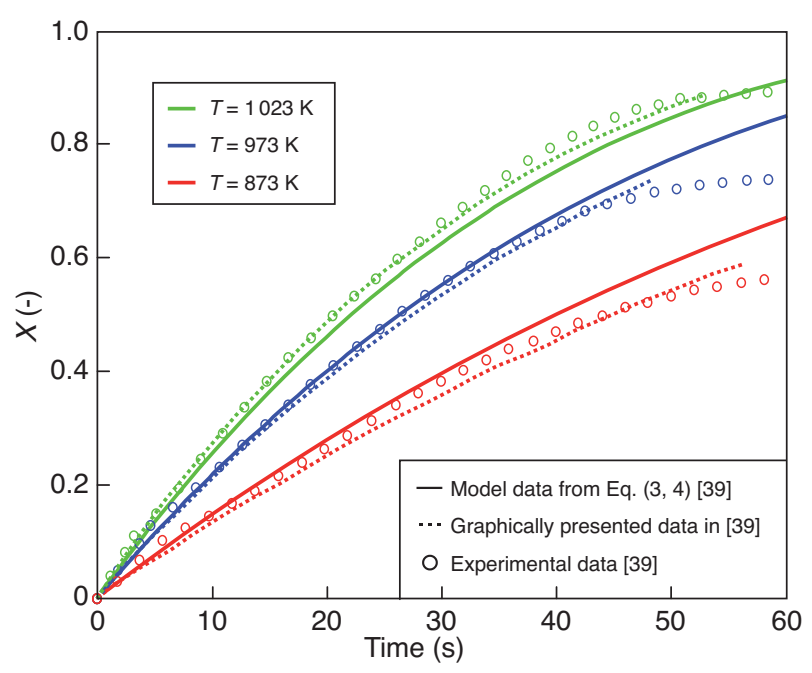

Figure 2

Discrepancy in modeled data given by Ryu et al. [39] for the conversion of $\mathrm{NiO}$ particles calculated through Equations $(3,4)$ and as graphically stated in the original paper in regard to their experimental results.

It is noticeable that conversion is represented too low at high temperatures and exaggerated for low temperatures based in Equations $(3,4)$ and not as good as stated by Ryu et al. [39]. The kinetic data from Equation (4) is used in the CFD-based study of Jung and Gamwo [38].

To calculate the reaction rate, Jung and Gamwo use an equation as given below where $S_{0}$ is the surface area with:

$$
r=-k S_{0} \varepsilon_{g} \frac{\rho_{g} Y_{\mathrm{CH}_{4}}}{M_{\mathrm{CH}_{4}}}=-k S_{0} \varepsilon_{g} C_{\mathrm{CH}_{4}}
$$




$$
S_{0}=\frac{6}{d_{p}} \varepsilon_{S} Y_{\mathrm{O}_{2}}
$$

The given equation for the reaction rate is linearly dependent on the gas fraction $\varepsilon_{g}$. The surface area $S_{0}$ is also linearly dependent on the mass fraction of oxygen $Y_{\mathrm{O}_{2}}$ which is the bonded oxygen within the $\mathrm{NiO}$. The bonded oxygen is a measure for the degree of conversion of the carrier material. Other authors like Levenspiel [40] or Syamlal [41] define the rate of reaction differently. Firstly they keep $r$ independent of $\varepsilon_{g}$ :

$$
r=-k S_{0} \frac{\rho_{g} Y_{\mathrm{CH}_{4}}}{M_{\mathrm{CH}_{4}}}=-k S_{0} C_{\mathrm{CH}_{4}}
$$

Secondly due to the fact that an unreacted shrinking core model is used $S_{0}$ is dependent on the degree of conversion $X$ through a nonlinear relation with:

$$
S_{0}=\frac{6}{d_{p}} \varepsilon_{S}(1-X)^{2 / 3}
$$

where $X$ is the volumetric dimensionless degree of conversion. The degree of conversion $X$ is on the one hand linked with the ratio between the radial position of the reaction front within the particle $r_{c}$ and the particle radius $r_{p}$ and on the other hand with the mass fractions $Y$ of $\mathrm{Ni}$ and $\mathrm{NiO}$ through:

$$
(1-X)^{1 / 3}=r_{c} / r_{p}=\left(Y_{\mathrm{Ni}} / \rho_{\mathrm{Ni}} / /\left(Y_{\mathrm{Ni}} / \rho_{\mathrm{Ni}}+Y_{\mathrm{NiO}} / \rho_{\mathrm{NiO}}\right)\right.
$$

The differences in modeling with both approaches, the sets of Equations $(5,6)$ and (7-9) are outlined in Figure 3. Following the assumption of the unreacted shrinking core model experimentally expected reaction rates (circles) are scaled by $2 / 3$ due to the fact, that Jung and Gamwo use particles of $r_{p}=120 \mu \mathrm{m}$ instead of $r_{p}=80 \mu \mathrm{m}$ as used by Ryu et al. [39]. Reaction rates calculated from Equations (5, 6) are shown as dashed lines, rates calculated from Equations (7-9) are plotted as solid lines.

For comparison two different gas fractions are considered with $\varepsilon_{g}=0.4$ in Figure $3 \mathrm{a}$ and $\varepsilon_{g}=0.8$ in Figure $3 \mathrm{~b}$. Experimentally derived reaction rates for both cases differ due to different values calculated for $S_{0}$. The model based in Equations $(5,6)$ underpredicts the reaction rates strongly for low gas fractions. In case of larger gas fractions the deviation between both models tends to become smaller. Due to the linear dependency of the reaction rate on the conversion the model by Jung and Gamwo [38] produces significantly different results compared to nonlinear models following Levenspiel [40] or Syamlal [41].

A further example of multi-phase CFD modelling applied to chemical looping combustion processes is given by Deng et al. [42, 43] and Jin et al. [44]. The authors were interested in the capabilities of $\mathrm{CaS}$ as an oxygen carrier material. The reduction and oxidation of the carrier material are given by the two reactions:

$$
\begin{gathered}
\mathrm{CaSO}_{4}+4 \mathrm{H}_{2} \rightarrow \mathrm{CaS}+4 \mathrm{H}_{2} \mathrm{O} \\
\mathrm{CaS}+2 \mathrm{O}_{2} \rightarrow \mathrm{CaSO}_{4}
\end{gathered}
$$

Deng, Jin and coworkers are only interested in the fuel reactor reaction (10). For the modeling of the kinetics they rely on data by Kim and Sohn [18]. Kim and Sohn suggest the use of the Avrami-Erofeev nucleation growth model with:

$$
t=1 / k^{\prime} \cdot(-\ln (1-X))^{1 / m}
$$

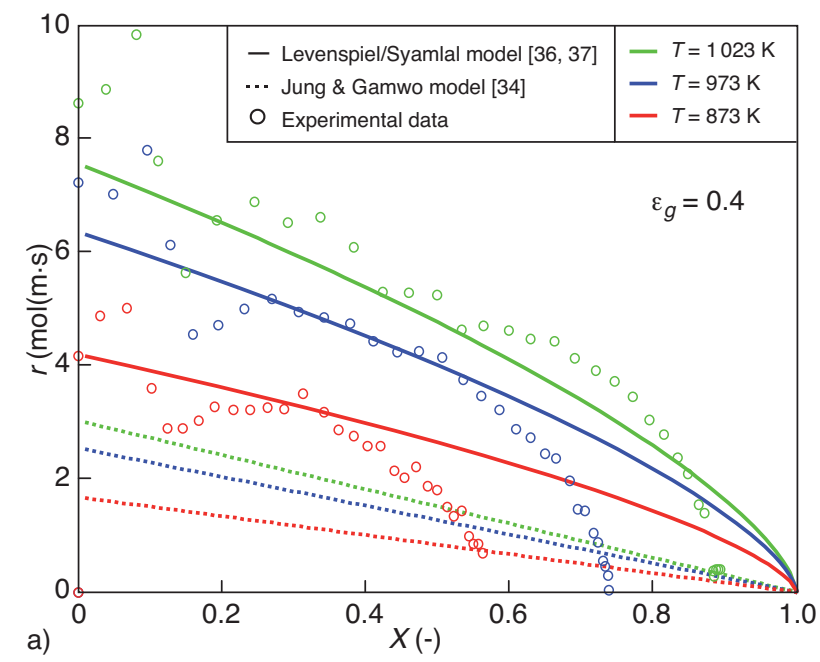

Figure 3

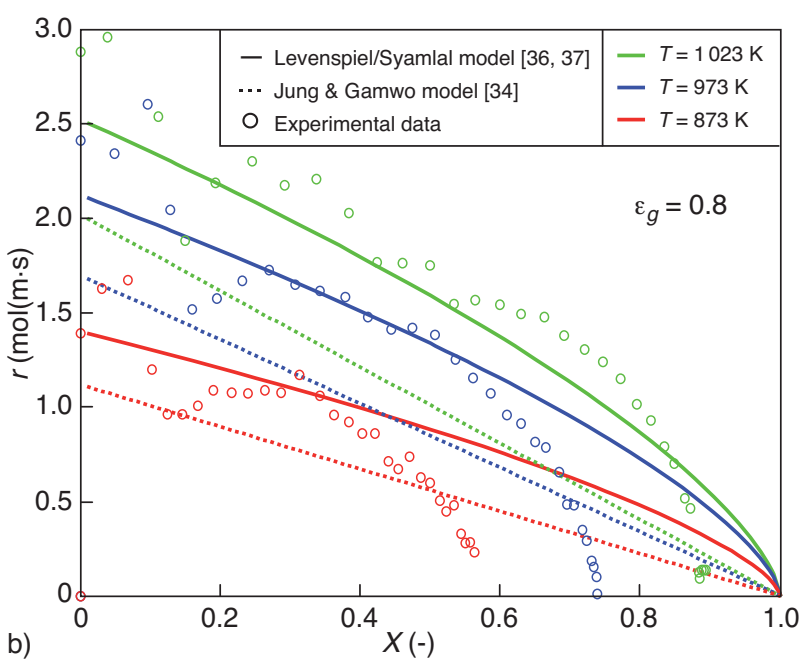

b)

Reaction rate as obtained from literature from Ryu et al. [39] scaled by particle size and calculated from Equations $(5,6)$ following Jung and Gamwo [38] and motivated by Equations (7-9) as suggested by Levenspiel [40] and Syamlal et al. [41]: a) $\varepsilon_{g}=0.4$ and b) $\varepsilon_{g}=0.8$. 
where the kinetic reaction constant $k^{\prime}$ in $(1 / \mathrm{s})$ is given as:

$$
k^{\prime}=k_{1} \cdot p_{\mathrm{H}_{2}} \cdot e^{-\frac{E}{R \cdot T}}
$$

where $R=8.314472 \mathrm{~J} / \mathrm{mol} \cdot \mathrm{K}^{-1}$ is the gas constant, $E=151 \mathrm{~kJ} / \mathrm{kmol}$ the activation energy, $k_{1}=70.83 \cdot 1 /(\mathrm{s} \cdot \mathrm{kPa})$ and $m=1.16$ with $T$ given in $(\mathrm{K})$ and $p$ in $(\mathrm{kPa})$. Deng and coworkers, however, do not use an Avrami-Erofeev model but apply its kinetic constant to a linear shrinking core model written as:

$$
\mathrm{t}=X / k^{\prime}
$$

Figure 4 reveals the effects of applying the kinetic constant from the Avrami-Erofeev model to a linear model without any adjustment. In general a linear model (dashed line) is only to a very limited extent able to represent the experimental conversion data of $\mathrm{CaSO}_{4}$ derived for varying $\mathrm{H}_{2}$ concentrations and different temperatures. In contrast the Avrami-Erofeev model (solid line) is quite capable of doing this. Far more striking is the fact that the slopes and thereby the reaction rates at large gas concentrations and high temperatures are strongly overpredicted through the use of the kinetic constants within a linear model.

\subsection{Macroscopic Continuum Models}

In contrast to the previous approaches macroscopic continuum models which are the least accurate, but the most computational efficient methods are based on separating the computational domain in the different reaction vessels into different zones which are further simplifications of the cell structure used in
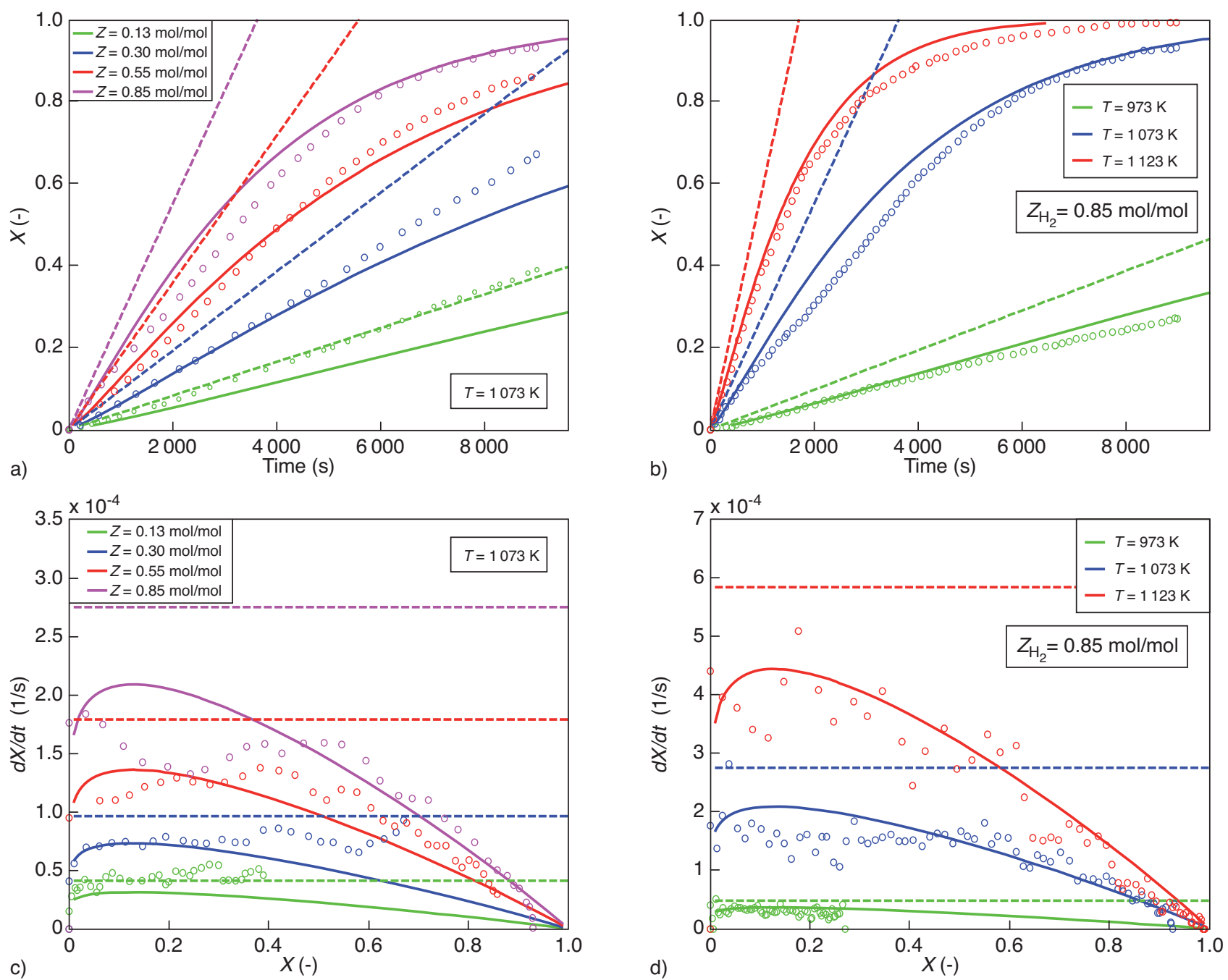

Figure 4

Degree of conversion (a, c) and conversion rate (b, d) for $\mathrm{CaSO}_{4}$ as modeled and experimentally obtained from Kim and Sohn [18] and as modeled by Deng et al. [42, 43] with gas temperature $T$ and molar fraction $Z$ of the gaseous reactant: (---) model used by Deng et al., $(\rightarrow$ Avrami-Erofeev model and experimental data $(0)$ derived from Kim and Sohn. 
the multi-phase CFD approaches. Formation of internal structures within the domain like bubbles or the development of gradients within one zone is often not resolved. However, the interaction of vessels through the circulation of carrier material can be considered in a transient way. These models found application by Xu et al. [45], Bolhar-Nordenkampf [46] or Kolbitsch [47] for fluidized systems and by Noorman et al. [16] for packed beds.

\section{APPLIED SIMULATION FRAMEWORK}

As the mathematical model framework in the study here a two-phase CFD approach is applied consisting of a gaseous and a particle phase. Balance equations are solved for each individual phase regarding the exchange of momentum, heat and mass transfer. The solid phase is modeled based on the kinetic theory of granular flow. As framework the commercial CFD-software Fluent 6.3.16 is used. Details on the underlying equations can be found in $[38,48,49]$.

\subsection{Modeling of the Reaction Kinetics}

For chemical looping combustion mainly two types of models are widely applied for both the oxidation and the reduction of the carrier material: Shrinking core models and nucleation growth models. The shrinking core models can be further divided into different groups depending on their governing mechanisms and the involved geometrical shape of the carrier. For further details see Hossaina and de Lasa [20] and Levenspiel [40]. Already introduced in the previous sections are the reaction based spherical shrinking core approach through Equation (3), the reaction based linear shrinking core approach through Equation (14) and the nucleation growth model through Equation (12).

The conversion rates for the spherical and linear shrinking core approach and the nucleation growth model can be calculated as:

$$
\begin{gathered}
d X / d t_{S S C}=3 \cdot b \cdot k^{\prime \prime} \cdot \exp \left(-\frac{E}{R \cdot T}\right) \cdot C_{g a s}^{n}(1-X)^{2 / 3} \\
d X / d t_{L S C}=b \cdot k^{\prime \prime} \cdot \exp \left(-\frac{E}{R \cdot T}\right) \cdot C_{g a s}^{n} \\
d X / d t_{A E}=-m \cdot 1 / b \cdot k^{\prime \prime} \cdot C_{g a s}^{n} \cdot \exp \left(-\frac{E}{R \cdot T}\right) . \\
(X-1)(-\ln (1-X))^{\left(\frac{m-1}{m}\right)}
\end{gathered}
$$

with the stoichiometric coefficient of the solid reactant $b$ and $C_{\text {gas }}$ the bulk concentration of the gaseous reactant.

In addition to these models Kruggel-Emden et al. [50] recently suggested the application of empirical polynomial based models for the representation of the reaction rate.
These models are enabling a more accurate representation of the dependency of the reaction rate on the degree of conversion especially considering the fact that not always a full conversion of the carrier material is possible:

$$
\begin{gathered}
d X / d t_{M P}=\sum_{n=1}^{l} a_{n}\left(X / X_{\text {ref }}\right)^{b_{n}}\left(Y_{\text {gas }} / Y_{\text {gasref }}\right)^{c_{n}}\left(T / T_{\text {ref }}\right)^{d_{n}}+ \\
\sum_{m=1+l}^{2 l} a_{m}\left(Y_{\text {gas }} / Y_{\text {gassef }}\right)^{b_{m}}\left(T / T_{\text {ref }}\right)^{c_{m}}
\end{gathered}
$$

Here $a_{n}, b_{n}, c_{n}, d_{n}, a_{m}, b_{m}, c_{m}$ are empirical coefficients, $Y_{g a s}$ is the bulk mass fraction of the gaseous reactant and $T_{\text {ref }}$, $X_{\text {ref }}, Y_{\text {gasref }}$ reference values to make $T / T_{\text {ref }}, \mathrm{X} / X_{\text {ref }}, Y_{\text {gas }} / Y_{\text {gasref }}$ dimensionless. For all applied models the heterogeneous reaction rate is important for the determination of the mass transfer between both solid and fluid phase and for the species transport equation given as:

$$
r_{h e}=1 / b \cdot d X / d t \cdot C_{M e 0}
$$

\subsection{Simulation Parameters}

The set of partial differential equations for the two-phase framework are solved through the finite volume method. The pressure-velocity coupling for both fluid and solid phase is realized through the phase coupled SIMPLE algorithm. The second-order-upwind-method was employed. A schematic of the fluidized bed is outlined in Figure 5 .

The gas inlet is defined through a uniform velocity inlet. The gas leaves the vessel through an outlet at the top of the vessel. The domain was discretized through 2500 rectangular cells in 2D. Grid refinement was tested and has only minor effect on the flow behavior. A time step of $0.0001 \mathrm{~s}$ was

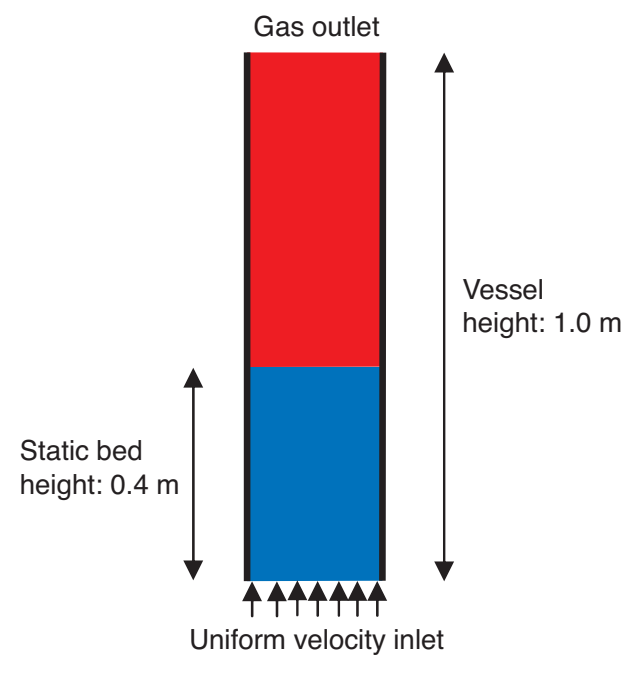

Figure 5

Schematic of the investigated fluidized bed. 
selected to ensure a convergence criterion of $10^{-3}$ for all quantities. The standard $k-\varepsilon$ model was used for both fluid and solid phase with a standard wall function to model for turbulence. For details on the use of a $k-\varepsilon$ model within a two-phase framework see Gryczka et al. [37]. Fluid particle momentum exchange was model through the approach by Gidaspow and heat transfer by the model of Gunn as outlined in [48]. The general simulation parameters are stated in Table 1.

Three different materials $\mathrm{CaSO}_{4}, \mathrm{Mn}_{3} \mathrm{O}_{4}$ and $\mathrm{NiO}$ were selected as carrier. Deliberately $\mathrm{CaSO}_{4}$ was chosen as applied in the studies by Deng et al. [42,43] and $\mathrm{NiO}$ as used by Jung and Gamwo [38]. The simulation conditions are selected similar to those by Deng et al. [42, 43]. An outline of the material sensitive simulation parameters is given in Table 2. The parameters used for the adjustment of the kinetic models (15-18) are given in Kruggel-Emden et al. [50].

\section{TABLE 1}

General system properties and parameters for the simulations

\begin{tabular}{c|c}
\hline Width of vessel $(\mathrm{m})$ & 0.25 \\
\hline Height of vessel $(\mathrm{m})$ & 1.0 \\
\hline Initial bed height $(\mathrm{m})$ & 0.4 \\
\hline Initial solids packing $(-)$ & 0.48 \\
\hline Angle of internal friction $\xi\left(^{\circ}\right)$ & 30 \\
\hline Maximal packing limit $\varepsilon_{s, \max }(-)$ & 0.6 \\
\hline Restitution coefficient e $(-)$ & 0.9 \\
\hline Grid number $(-)$ & 2500 \\
\hline Grid size $(\mathrm{m})$ & $0.01 \times 0.01$ \\
\hline Time interval $(\mathrm{s})$ & 0.0001 \\
\hline
\end{tabular}

TABLE 2

Oxygen carrier material sensitive simulation parameters

\begin{tabular}{|c|c|}
\hline \multicolumn{2}{|c|}{ Reduction of $\mathrm{CaSO}_{4}$} \\
\hline Governing reaction & $\mathrm{CaSO}_{4}+4 \mathrm{H}_{2} \rightarrow \mathrm{CaS}+4 \mathrm{H}_{2} \mathrm{O}$ \\
\hline Inlet gas velocity $(\mathrm{m} / \mathrm{s})$ & $0.32 ; 0.9$ \\
\hline Inlet gas composition (\%) & $\mathrm{H}_{2}: 100 ; \mathrm{H}_{2} \mathrm{O}: 0$ \\
\hline Initial solid phase composition (\%) & $\mathrm{CaSO}_{4}: 100 ; \mathrm{CaS}: 0$ \\
\hline Particle diameter (mm) & 0.275 \\
\hline Initial solid temperature $(\mathrm{K})$ & 1123 \\
\hline Inlet gas temperature $(\mathrm{K})$ & 1123 \\
\hline \multicolumn{2}{|c|}{ Reduction of $\mathrm{Mn}_{3} \mathrm{O}_{4}$} \\
\hline Governing reaction & $4 \mathrm{Mn}_{3} \mathrm{O}_{4}+\mathrm{CH}_{4} \rightarrow 12 \mathrm{MnO}+\mathrm{CO}_{2}+2 \mathrm{H}_{2} \mathrm{O}$ \\
\hline Inlet gas velocity (m/s) & 0.3 \\
\hline Inlet gas composition for $t<1 \mathrm{~s} \mathrm{( \% )}$ & $\mathrm{CH}_{4}: 0 ; \mathrm{H}_{2} \mathrm{O}: 0 ; \mathrm{CO}_{2}: 100$ \\
\hline Inlet gas composition for $t>1 \mathrm{~s} \mathrm{( \% )}$ & $\mathrm{CH}_{4}: 8.352 ; \mathrm{H}_{2} \mathrm{O}: 0 ; \mathrm{CO}_{2}: 91.648$ \\
\hline Initial solid phase composition for $X=0(\%)$ & $\mathrm{ZrO}_{2}: 59.98 ; \mathrm{Mn}_{3} \mathrm{O}_{4}: 39.99 ; \mathrm{MnO}: 0$; Air: 0.03 \\
\hline Initial solid phase composition for $X=0.8(\%)$ & $\mathrm{ZrO}_{2}: 57.4 ; \mathrm{Mn}_{3} \mathrm{O}_{4}: 7.65 ; \mathrm{MnO}: 34.9 ;$ Air: 0.03 \\
\hline Particle diameter (mm) & 0.1525 \\
\hline Initial solid temperature $(\mathrm{K})$ & 1223 \\
\hline Inlet gas temperature $(\mathrm{K})$ & 1223 \\
\hline \multicolumn{2}{|c|}{ Reduction of $\mathrm{NiO}$} \\
\hline Governing reaction & $4 \mathrm{NiO}+\mathrm{CH}_{4} \rightarrow \mathrm{CO}_{2}+2 \mathrm{H}_{2} \mathrm{O}+4 \mathrm{Ni}$ \\
\hline Inlet gas velocity (m/s) & 0.3 \\
\hline Inlet gas composition for $t<1 \mathrm{~s}(\%)$ & $\mathrm{CH}_{4}: 0 ; \mathrm{H}_{2} \mathrm{O}: 0 ; \mathrm{CO}_{2}: 100$ \\
\hline Inlet gas composition for $t>1 \mathrm{~s} \mathrm{( \% )}$ & $\mathrm{CH}_{4}: 8.352 ; \mathrm{H}_{2} \mathrm{O}: 0 ; \mathrm{CO}_{2}: 91.648$ \\
\hline Initial solid phase composition for $X=0(\%)$ & $\mathrm{MgAl}_{2} \mathrm{O}_{4}: 59.99 ; \mathrm{NiO}: 39.99 ; \mathrm{Ni}:$; Air: 0.02 \\
\hline Initial solid phase composition for $X=0.8(\%)$ & $\mathrm{MgAl}_{2} \mathrm{O}_{4}: 54.17 ; \mathrm{NiO}: 7.22 ; \mathrm{Ni}: 38.6$; Air: 0.01 \\
\hline Particle diameter (mm) & 0.1525 \\
\hline Initial solid temperature $(\mathrm{K})$ & 1223 \\
\hline Inlet gas temperature $(\mathrm{K})$ & 1223 \\
\hline
\end{tabular}




\section{COMPUTATIONAL RESULTS AND DISCUSSION}

\subsection{Reduction of the Carrier Material $\mathrm{CaSO}_{4}$}

As a first test case $\mathrm{CaSO}_{4}$ was fluidized in a reactor with gas velocities of $v=0.32 \mathrm{~m} / \mathrm{s}$ and $v=0.9 \mathrm{~m} / \mathrm{s}$. A gas velocity of $v=0.32 \mathrm{~m} / \mathrm{s}$ was initially proposed by Deng et al. [43] which is however very close to the fluidization limit. Therefore a larger velocity of $v=0.9 \mathrm{~m} / \mathrm{s}$ was also considered lying in the slugging regime guaranteeing for a stronger dynamics within the vessel. Figure 6 outlines data on the conversion speed of $\mathrm{CaSO}_{4}$ derived from experimental results by Kim and Sohn [18]. The four different reaction models introduced in Section 2.1 were adjusted to the experimental data. Details can be found in Kruggel-Emden et al. [50]. Results indicate that all three the Avrami-Erofeev, the spherical shrinking core and the multi parameter model are quite capable of modeling the reaction kinetics over wide ranges of conversion. It is, however, difficult to pinpoint the best model among these three. Particularly at very low degrees of conversion the experimental data favors the nucleation growth model at certain temperature levels and gas concentrations, which leads to a zero conversion rate at zero conversion in the model. However, at other temperatures and concentrations this conclusion can not be drawn. It is obvious from the progression of the conversion speed that the use of a linear shrinking core model is not suitable over wider conversion ranges.

Results for the mass fraction of $\mathrm{H}_{2}$ and mass fraction $\mathrm{H}_{2} \mathrm{O}$ both considered at the outlet of the vessel and the mass fraction of $\mathrm{CaS}$ in the solid phase are plotted over time in Figure 7. Figures $(7 \mathrm{a}, \mathrm{c}, \mathrm{e})$ are thereby related to the lower velocity of $v=0.32 \mathrm{~m} / \mathrm{s}$ and Figures $(7 \mathrm{~b}, \mathrm{~d}, \mathrm{f})$ related to the velocity of $v=0.9 \mathrm{~m} / \mathrm{s}$. Keeping in mind the slow reactivity of $\mathrm{CaSO}_{4}$, the time scales of just up to $10 \mathrm{~s}$ relate to only incrementally reacted $\mathrm{CaSO}_{4}$ and therefore a marginal degree of conversion $X$. As obvious from Figure 6 a low conversion results in significant differences between the reaction models for the reaction rate.

The fastest rates are reported by the spherical shrinking core model and the multi parameter model, followed by the linear shrinking core model adjusted to match a good overall reaction rate. The Avrami-Erofeev model results in low reaction rates at low degrees of conversion. With no full conversion of the fuel gas $\mathrm{H}_{2}$ achieved within the fluidized bed, results for the mass fractions of $\mathrm{H}_{2}$ and $\mathrm{H}_{2} \mathrm{O}$ at the outlet vary strongly being a result of the varying reaction rates predicted by Figure 6 . Although there are differences in the reaction rates for the multi parameter model and the spherical shrinking core approach, those do not get obvious from Figure 7 for the low gas velocity, but to some extend for the larger velocity. The oscillations in the outlet gas concentrations at the larger fluidization velocity are a result of the stronger dynamics within the fluidized bed due to stronger bubble formation
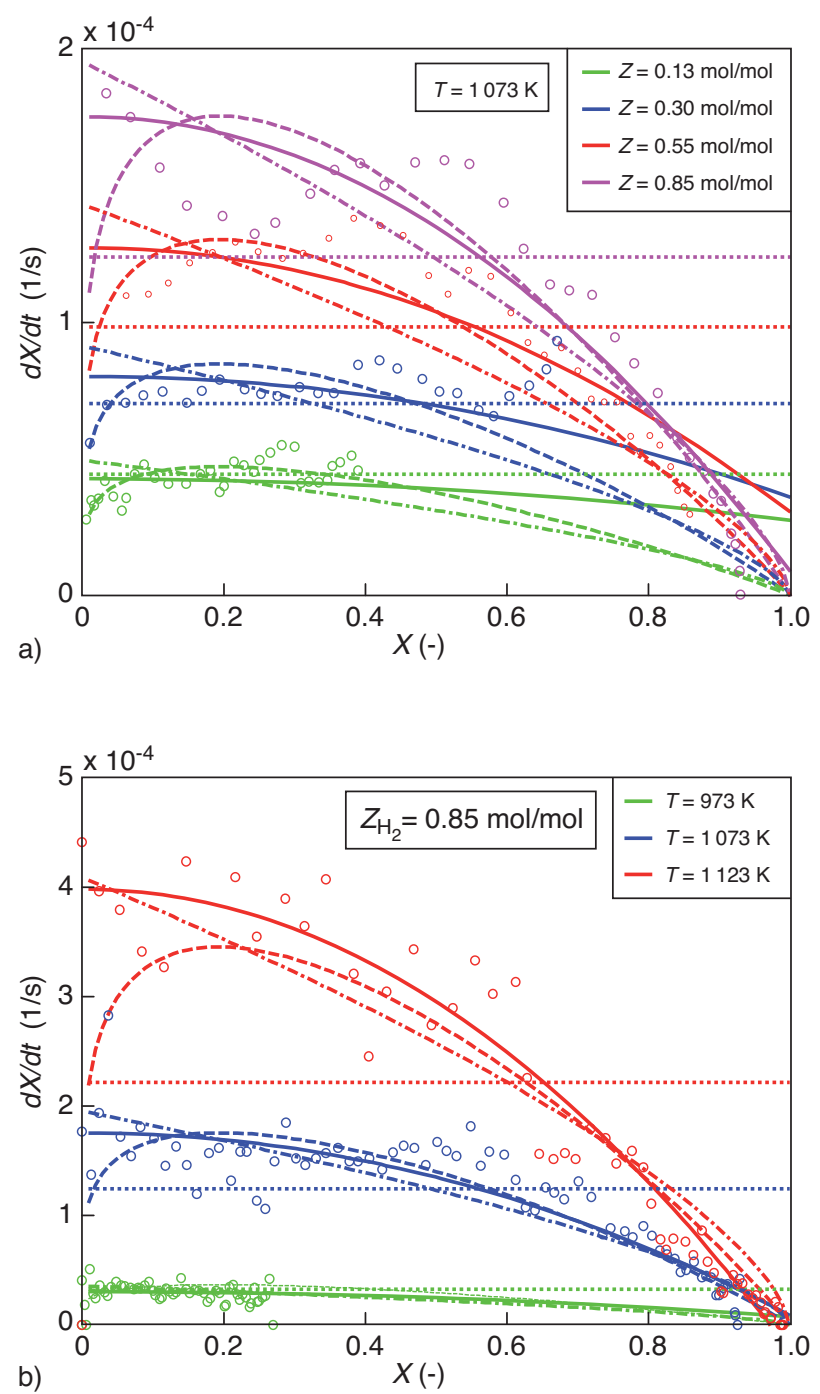

Figure 6

Conversion speed of $\mathrm{CaSO}_{4}$ with $\mathrm{H}_{2}$ at the gas temperature $T$ and molar fraction $\mathrm{Z}$ of $\mathrm{H}_{2}:(-\cdot)$ spherical shrinking core model, ( $\cdots)$ linear shrinking core model, (---) Avrami-Erofeev model, (-) multi parameter model, (O) experimental data derived by Kim and Sohn [18].

and slugging. Due to the fact of an incomplete conversion of the fuel gas different reaction models lead to differences in the amount of $\mathrm{CaS}$ formed within the fluidized bed and therefore of course in the progression of the overall conversion. Under the chosen operation conditions which were selected in accordance with Deng et al. [43] for the small fluidization velocity it is obvious that the times till full conversion of the solid phase vary strongly for the four investigated kinetic models.

Figure 8 shows a snapshot of the fuel gas concentration of $\mathrm{H}_{2}$ within the fluidized bed at $t=10 \mathrm{~s}$ for the two different fluidization velocities applied. Whereas at the low velocity a 

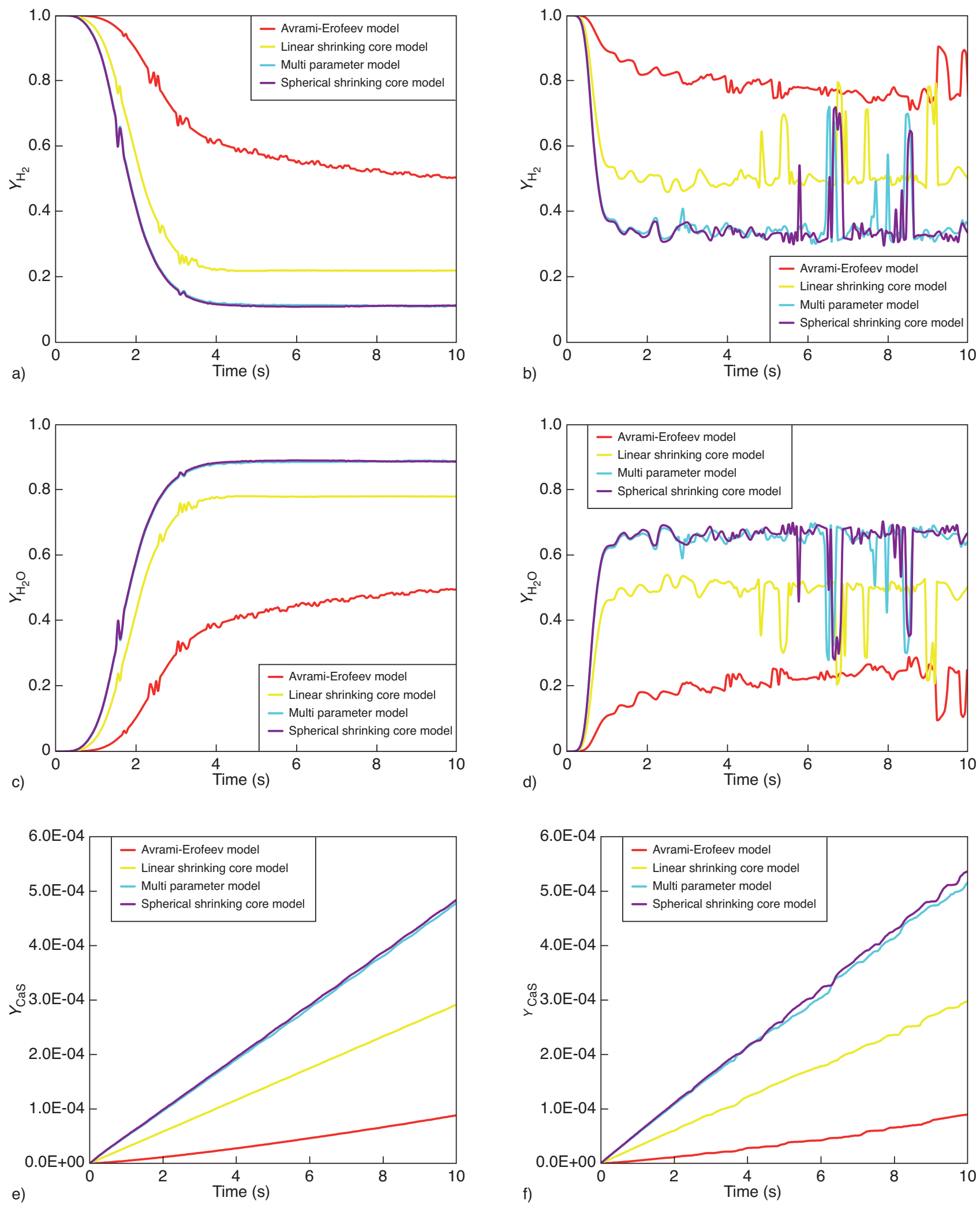

Figure 7

Mass fraction of $\mathrm{H}_{2}(\mathrm{a}, \mathrm{b})$ and mass fraction $\mathrm{H}_{2} \mathrm{O}(\mathrm{c}, \mathrm{d})$ at the outlet of the vessel and mass fraction of $\mathrm{CaS}$ (e, f) in the solid phase over time. Fuel inlet velocity: (a, c, e) $v=0.32 \mathrm{~m} / \mathrm{s}$ and (b, d, f) $v=0.9 \mathrm{~m} / \mathrm{s}$. 


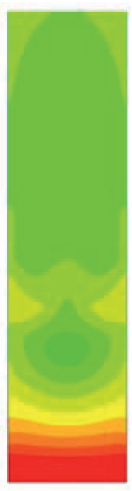

a)
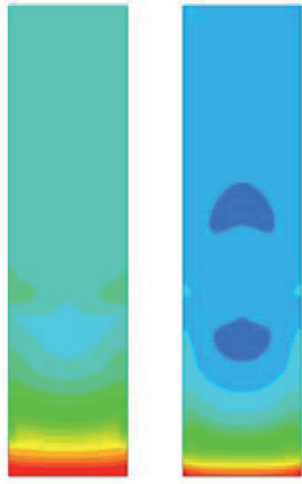

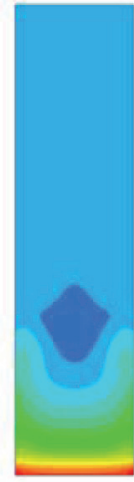

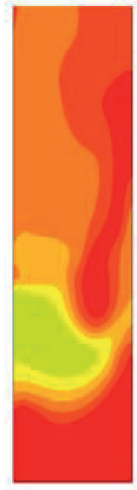

b)
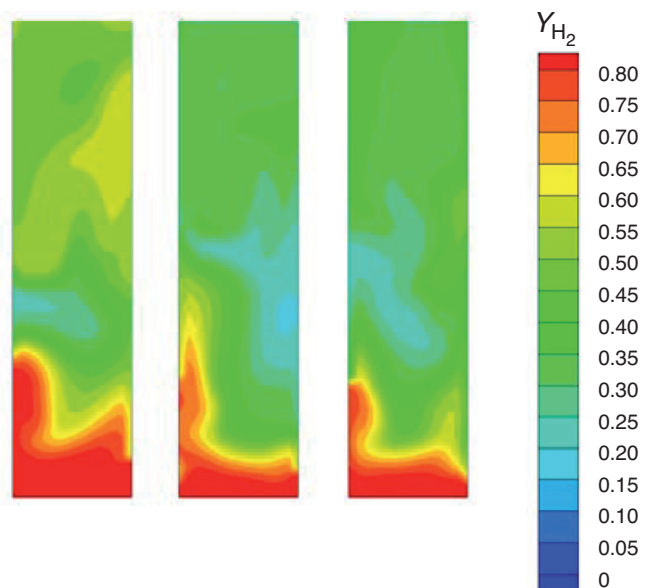

Figure 8

Mass fraction of $\mathrm{H}_{2}$ within the fluidized bed at $t=10 \mathrm{~s}:$ a) $\left.v=0.32 \mathrm{~m} / \mathrm{s}, \mathrm{b}\right) v=0.9 \mathrm{~m} / \mathrm{s}$. Reaction models from left to right: Avrami-Erofeev model, linear shrinking core model, multi parameter model and spherical shrinking core model.

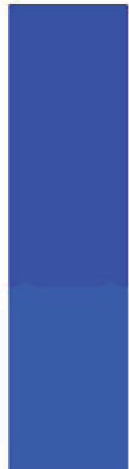

a)

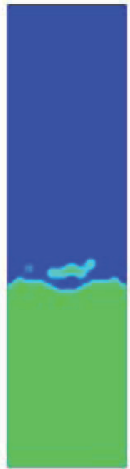

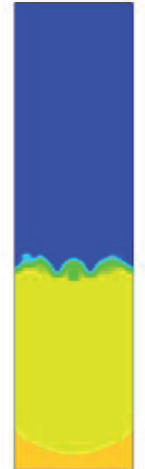

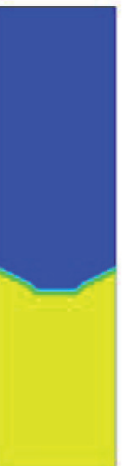

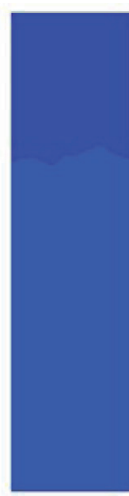

b)
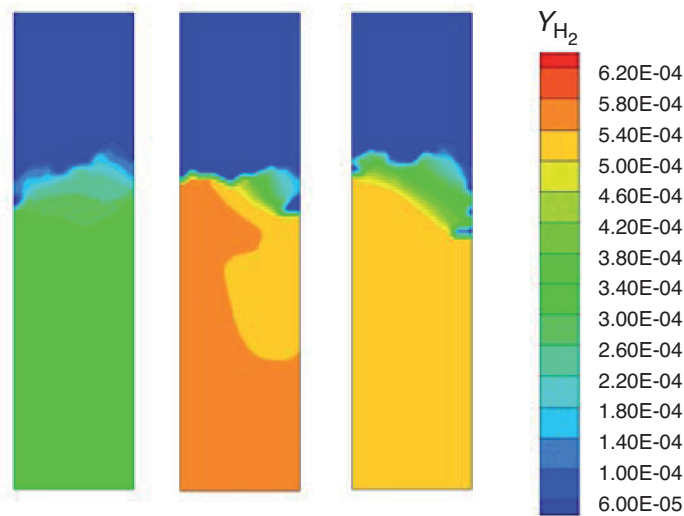

Figure 9

Mass fraction of $\mathrm{CaS}$ within the fluidized bed at $t=10 \mathrm{~s}$ : a) $v=0.32 \mathrm{~m} / \mathrm{s}$, b) $v=0.9 \mathrm{~m} / \mathrm{s}$. Reaction models from left to right: Avrami-Erofeev model, linear shrinking core model, multi parameter model and spherical shrinking core model.

clear lamellar reaction zone can be identified it gets frayed at the larger velocity. Different reaction models lead to differently large reaction zones.

In Figure 9, a snapshot of the concentration of $\mathrm{CaS}$ within the vessel at $t=10 \mathrm{~s}$ is displayed. The distribution of the different concentrations of CaS within the solid phase is very homogenous outlining a strong mixing within the solid phase. Already after the short simulation time of $t=10 \mathrm{~s}$ applied different models lead to significant different concentrations of $\mathrm{CaS}$ within the solid phase of the fluidized bed.

\subsection{Reduction of the Carrier Material $\mathrm{Mn}_{3} \mathrm{O}_{4}$}

As a second carrier material $\mathrm{Mn}_{3} \mathrm{O}_{4}$ was investigated which has a much higher reactivity than $\mathrm{CaSO}_{4}$ but has a low oxygen carrier capacity compared to other metal carrier materials
[20]. A fluidization velocity of $v=0.3 \mathrm{~m} / \mathrm{s}$ was selected. The behavior of $\mathrm{Mn}_{3} \mathrm{O}_{4}$ is firstly investigated for the fully unreacted carrier material of $X_{0}=0$ and later for a partly reacted material of $X_{0}=0.8$. In Figure 10, the speed of conversion of $\mathrm{Mn}_{3} \mathrm{O}_{4}$ over the degree of conversion is plotted. Similar to $\mathrm{CaSO}_{4}$ all three models as the Avrami-Erofeev, the spherical shrinking core and the multi parameter model give a fairly good representation of the experimental data derived from experiments by Zafar et al. [51] and Johansson et al. [52]. From the data a clear nucleation growth mechanism with a zero conversion rate at zero degree of conversion is not detectable. Additionally at low degrees of conversion the spherical shrinking core model leads to overstated reaction rates. Therefore best modeling of the kinetic data is achieved through the multi parameter model. The linear shrinking core model can be applied over narrow ranges of conversion but 

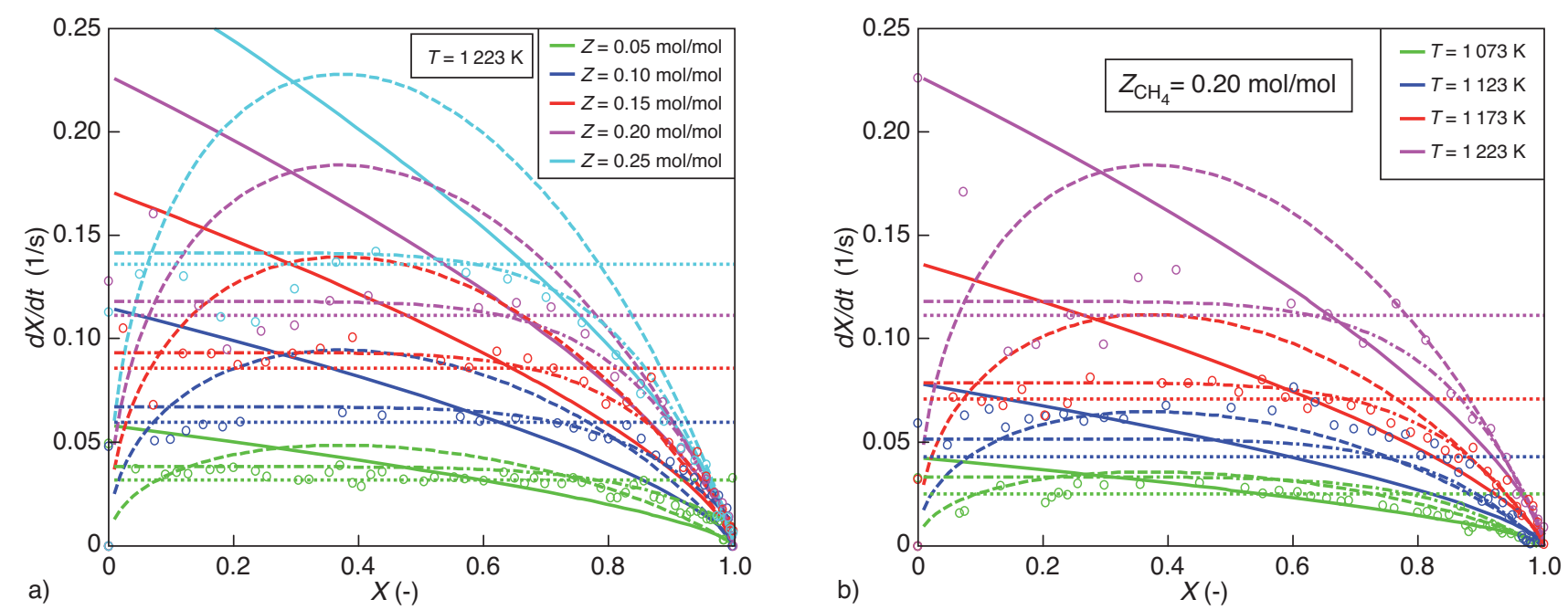

Figure 10

Conversion speed of $\mathrm{Mn}_{3} \mathrm{O}_{4}$ particles with $\mathrm{CH}_{4}$ at the gas temperature $T$ and molar fraction $Z$ of $\mathrm{CH}_{4}$ : (-) spherical shrinking core model, ( $\cdots$ ) linear shrinking core model, (---) Avrami-Erofeev model, (--) multi parameter model, (O) experimental data derived by Zafar $e t$ al. [51] and Johansson et al. [52].
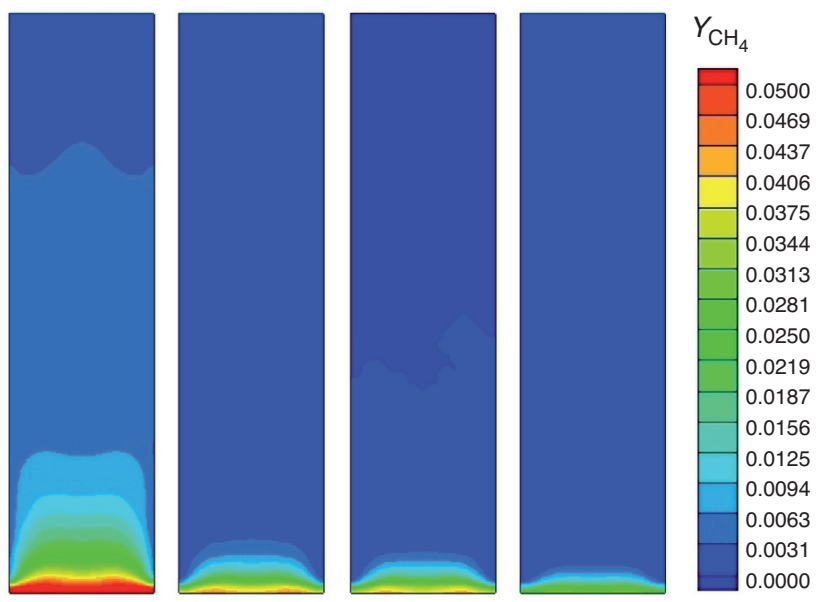

Figure 11

Mass fraction of $\mathrm{CH}_{4}$ within the fluidized bed at $t=2 \mathrm{~s}$. Reaction models from left to right: Avrami-Erofeev model, linear shrinking core model, multi parameter model and spherical shrinking core model.

fails when applied over larger intervals reporting a misleading constant conversion rate there.

Figure 11 gives a snapshot of the concentration of methane within the fluidized bed at $t=2 \mathrm{~s}$. The reaction of methane within the simulated bed setup is nearly complete. Despite the different reaction rates reported from different reaction models the outlet gas contains nearly no $\mathrm{CH}_{4}$ for all models. Different reactions models however result in differently pronounced reaction zones.
Results for the fully unreacted $\mathrm{Mn}_{3} \mathrm{O}_{4}$ are plotted in Figure 12. If the size of the reaction zone is defined as the area within the vessel's solid phase where the $\mathrm{CH}_{4}$ concentration is above a certain threshold selected as $Y>0.01$, than the size of the reaction zone can be calculated and plotted over time as shown in Figure 12a. The Avrami-Erofeev model results in a large reaction zone at low degrees of conversion which is declining over time. Eventually it becomes smaller than the sizes reported for the linear and the multi parameter model. The spherical shrinking core model leads to the smallest reaction zone corresponding to the fastest reaction rates. These results are in correspondence with prediction of the reaction rate over the degree of conversion displayed in Figure 10. Due to the fact that the conversion of methane within the fuel reactor is complete, the models reveal no differences in the mass fraction of $\mathrm{MnO}$ reported in the vessel over time as plotted in Figure 12b. Furthermore, both the average temperature within the solid phase and the gas outlet temperature which are declining over time due to the endothermic nature of the reaction, reveal no deviations as shown in Figures 12c and 12d.

In case of a advanced degree of conversion $\left(X_{0}=0.8\right)$ of the $\mathrm{Mn}_{3} \mathrm{O}_{4}$ results for the previously considered properties are significantly differing for the four reaction models. Figure 13a reveals insight into the size of the reaction zone over time assuming a limit of $Y>0.01$. From $X_{0}=0.8$ onwards the reaction rates are developing significantly different from each other (Fig. 10). In addition the content of $\mathrm{Mn}_{3} \mathrm{O}_{4}$ in the solid phase is dropping reducing the amount of oxygen that could be released. Both affects superpose and lead to a growing reaction zone. The Avrami-Erofeev model results in the 

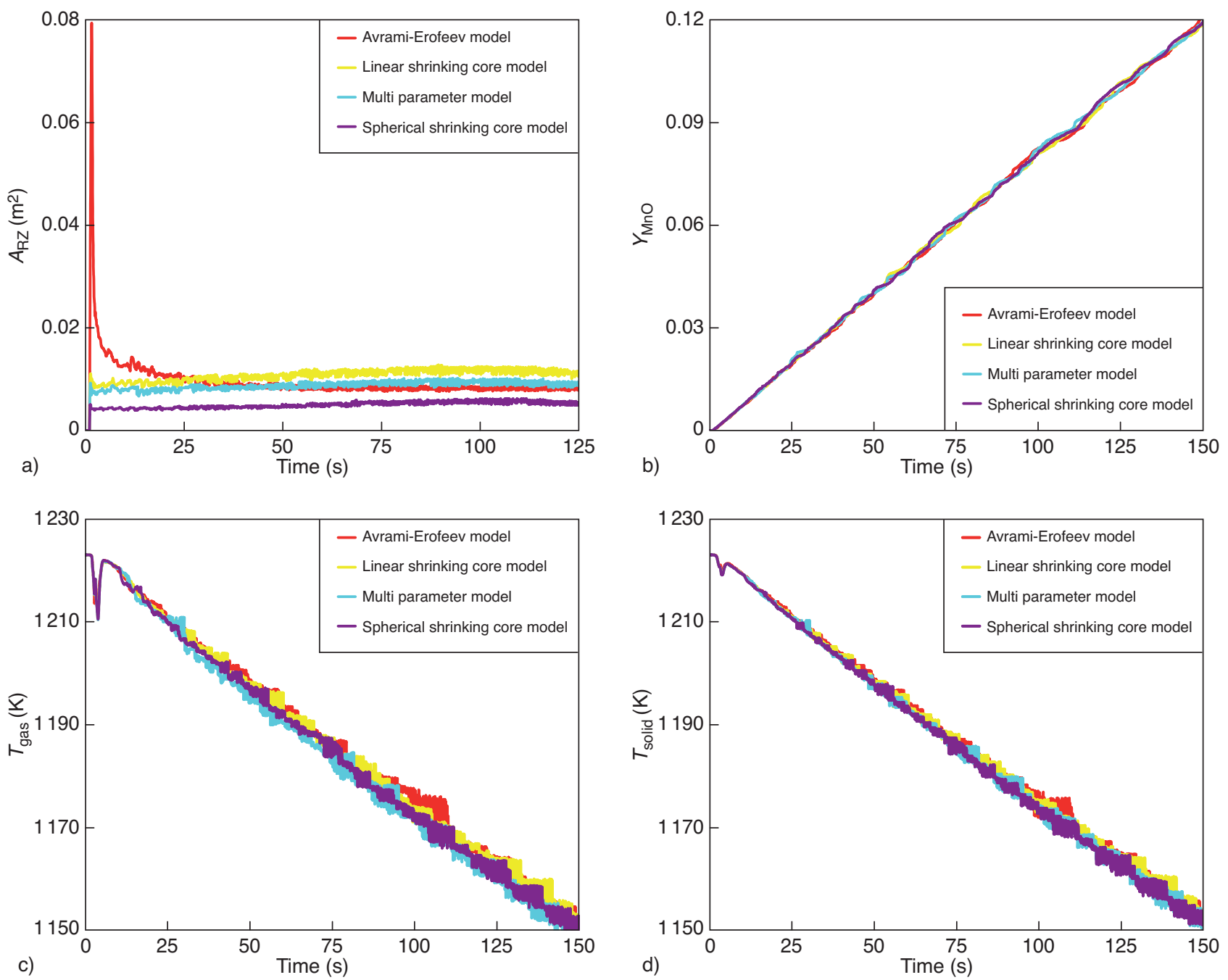

Figure 12

a) Area of the reaction zone, b) mass fraction of $\mathrm{MnO}$ in the solid phase, c) gas temperature at the outlet and d) temperature of the solid phase over time for $X_{0}=0$.

largest size increase of the reaction zone followed by the multi parameter model and the linear and spherical shrinking core model. The limiting value of $A_{R Z}=0.16 \mathrm{~m}^{2}$ is a consequence of the maximal extension of the dense bed region when fluidized. Figure $13 \mathrm{~b}$ gives insight into the $\mathrm{MnO}$ content of the solid phase. Starting with the same MnO content at $t=0 \mathrm{~s}$ the application of the different reaction models results in a varying $\mathrm{MnO}$ content of the solid phase over time. Figure $13 \mathrm{c}$ gives insight into the solid temperature. Due to the endothermic nature of the reaction the solid bed temperature is dropping over time. Due to the fact that the formation of $\mathrm{MnO}$ is different for the considered models the evolution of the solid temperature is also affected. It can be seen that after a certain time the solid temperature is rising again due to the fact, that the fluidizing methane/carbon dioxide mixture releases its heat which is not consumed through the earlier ongoing reaction. Figure $13 \mathrm{~d}$ shows the mass fraction of methane at the exit of the vessel. The incline of the mass fraction over time occurs in the same order as found in Figures 13a-c. Both shrinking core models, although starting with the less steep slope, reach the limiting methane concentration in the shortest time.

\subsection{Reduction of the Carrier Material NiO}

As a third example of a possible carrier material $\mathrm{NiO}$ is considered which was incorporated in the CFD-study by 

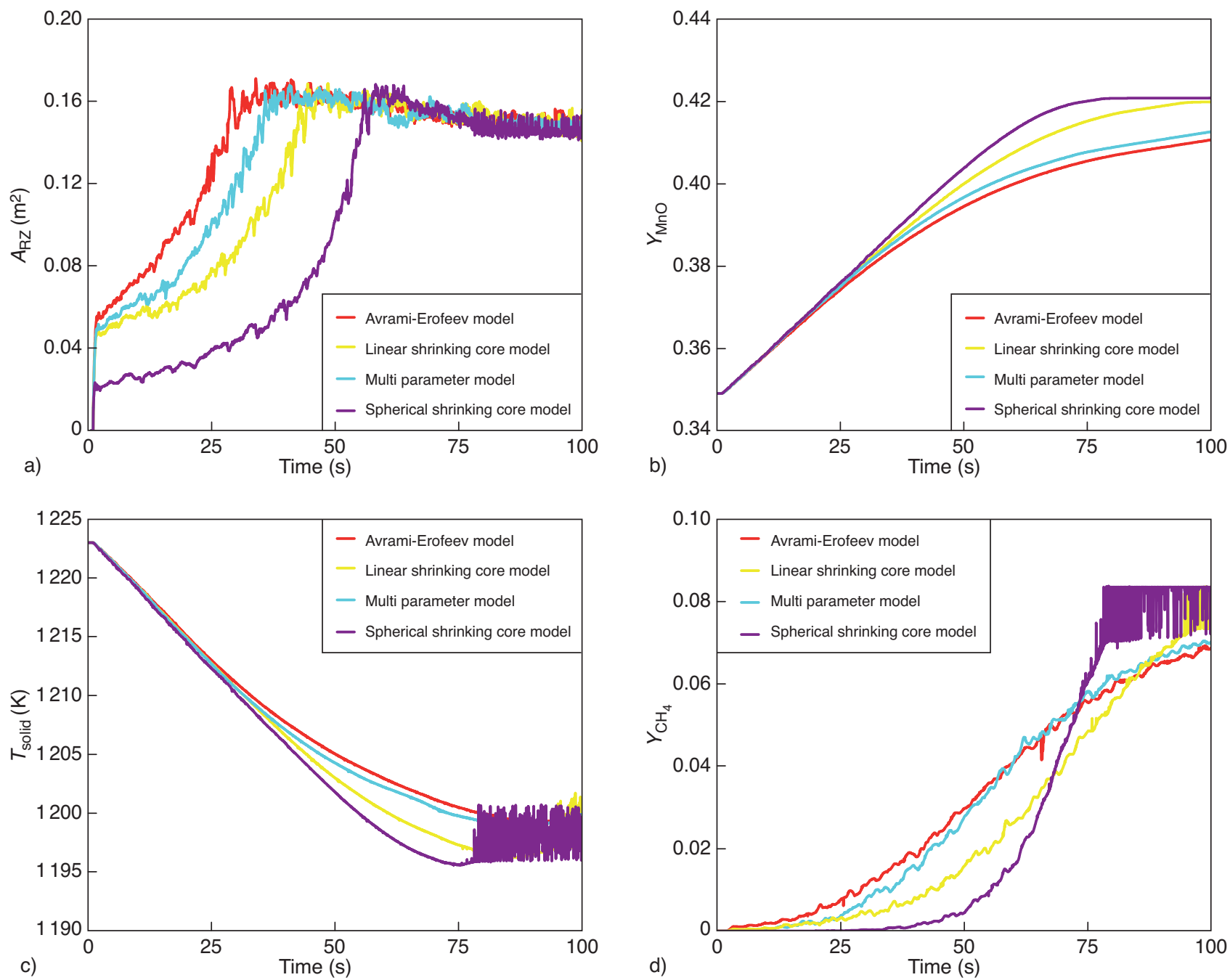

Figure 13

a) Area of the reaction zone, b) mass fraction of $\mathrm{MnO}$ in the solid phase, c) temperature of the solid phase and d) mass fraction of $\mathrm{CH}_{4}$ at the outlet over time for $X_{0}=0.8$.

Jung and Gamwo [38], however, based on kinetics data by Ryu et al. [39] there. Here, kinetic data of Zafar et al. [53] is used. Figure 14 gives insight into the evolution of the conversion rate over the degree of conversion for $\mathrm{NiO}$ being exposed to methane. For both the experimental data obtained at constant temperature and at constant molar fraction of methane it gets obvious that $\mathrm{NiO}$ does not fully convert to $\mathrm{Ni}$ under the conditions considered by Zafar et al. [53]. A nucleation growth mechanism is not visible from the plots with conversion rates at zero conversion not being zero. Therefore, the application of the Avrami-Erofeev model seems not feasible. The linear shrinking core model reports a constant conversion rate which can not be confirmed for larger ranges of conversion. The spherical shrinking core model strongly underpredicts the experimentally derived conversion rates especially for low degrees of conversion. All three classical models have the disadvantage, that they assume a full conversion of $\mathrm{NiO}$ which is apparently not the case. In contrast, the empirically derived multi parameter model gives a far better representation of the experimental data. It is capable of modeling the incomplete conversion of $\mathrm{NiO}$ towards larger degrees of conversion. However, even for this model some deviations are detectable at low temperatures at constant methane concentration. The overall behavior, however, is still very good.

At low degrees of conversion the reaction rates reported from the Avrami-Erofeev model are very low. This is resulting in a very elongated reaction zone. The extension of the 

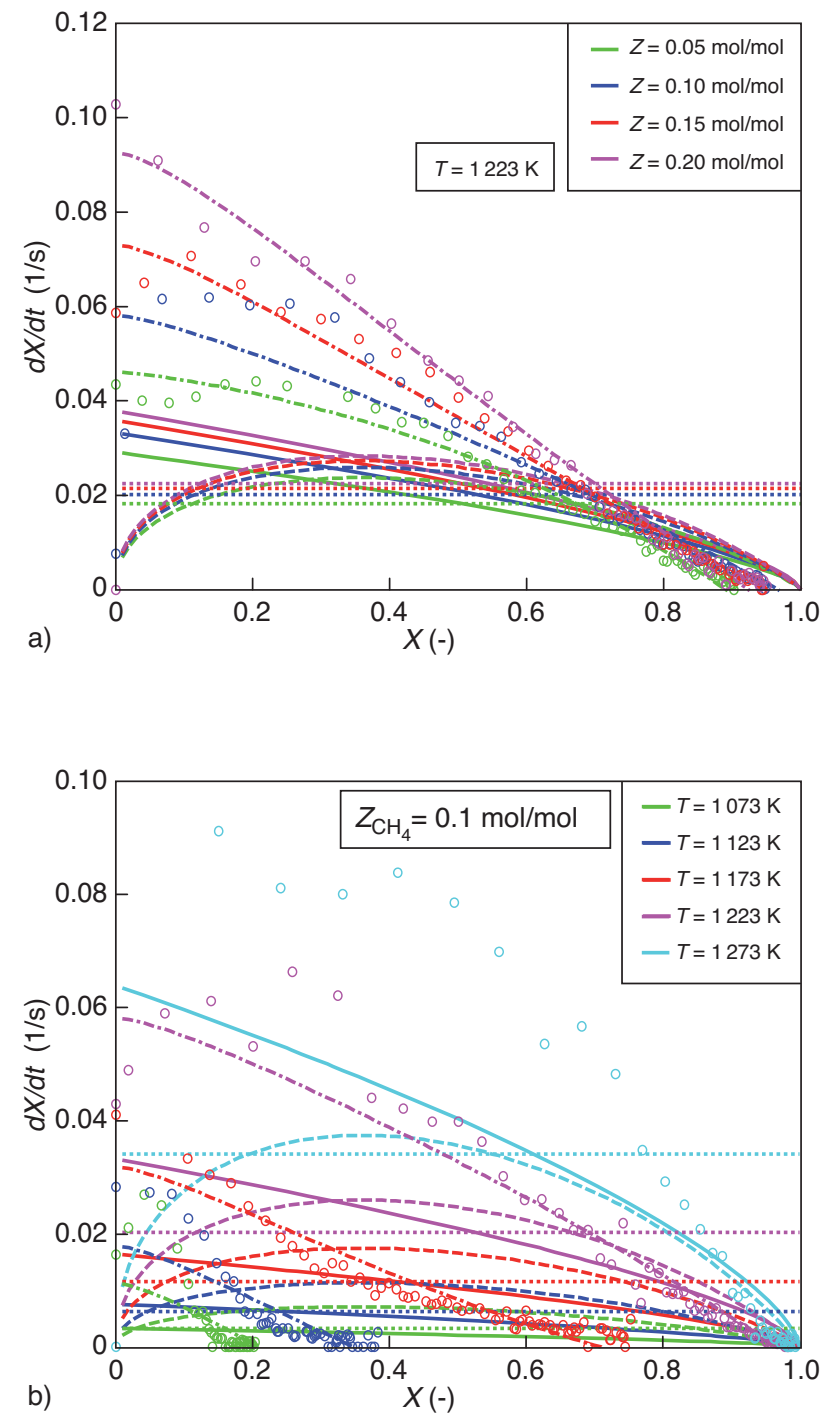

Figure 14

Conversion speed of $\mathrm{NiO}$ particles with $\mathrm{CH}_{4}$ at the gas temperature $T$ and molar fraction $Z$ of the gaseous reactant: $(-)$ spherical shrinking core model, ( $\cdots)$ linear shrinking core model, (--) Avrami-Erofeev model, (-•-) multi parameter model, (O) experimental data derived by Zafar et al. [58].

reaction zone is, however, sufficient small enough to guarantee full conversion of the methane as displayed in Figure 15. All other three models result in significantly smaller reactions zones with the multi parameter model having the smallest zone. These results are in agreement with the observations from Figure 14.

Results for the initially fully unreacted $\mathrm{NiO}$ are outlined in Figure 16. With the Avrami-Erofeev model reporting an increasing reaction rate with progressing conversion, the size
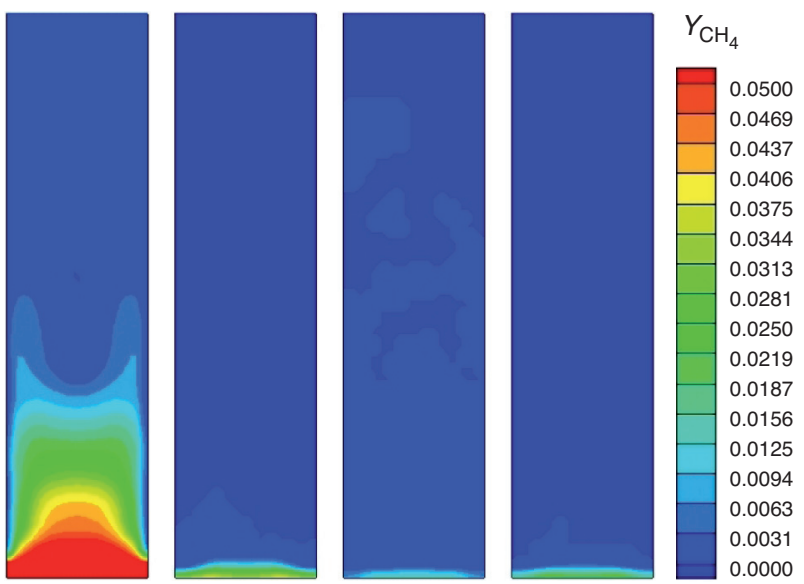

Figure 15

Mass fraction of $\mathrm{CH}_{4}$ within the fluidized bed at $t=2 \mathrm{~s}$. Reaction models from left to right: Avrami-Erofeev model, linear shrinking core model, multi parameter model and spherical shrinking core model.

of the reaction zone defined as the area where $Y>0.01$, is rapidly declining. At a certain progression a nearly equivalent large reaction zone is reported from all four models as shown in Figure 16a. With a full methane conversion being achieved within the vessel, the increase in Ni within the solid phase of the bed is the same for all four studied models (Fig. 16b). Due to this and the fact that the reaction zones are of comparable size, an equal decreases in temperature for both the gas phase and the solid phase are reported over time.

At an elevated degree of conversion $\left(X_{0}=0.8\right)$ studied in Figure 17 the overall reaction rate is reported so slow by the multi parameter model that the reaction zone expands over the whole dense phase region within the reaction vessel. At this point all other models still report a very fast reaction resulting in a small reaction zone as outlined in Figure 17a. The assumption of a fast reaction rate is made by the linear and the spherical shrinking core model over the whole range of considered simulation time. At $t=250 \mathrm{~s}$ the AvramiErofeev model reports a strong drop in reactivity resulting in an expansion of the reaction zone to the size reported by the multi parameter model. The methane concentration at the outlet is plotted in Figure 17b. Starting at $X_{0}=0.8$ no full conversion of methane is reported by the multi parameter model. The methane concentration is slowly increasing up to a point where the overall reaction stops and all injected methane is released unrendered from the vessel again. The same can be detected for the Avrami-Erofeev model where after $t>270 \mathrm{~s}$ all injected methane is released without reacting with the $\mathrm{NiO}$. The halt of the reaction also gets visible from the plot of the gas outlet temperature in Figure 17c. 

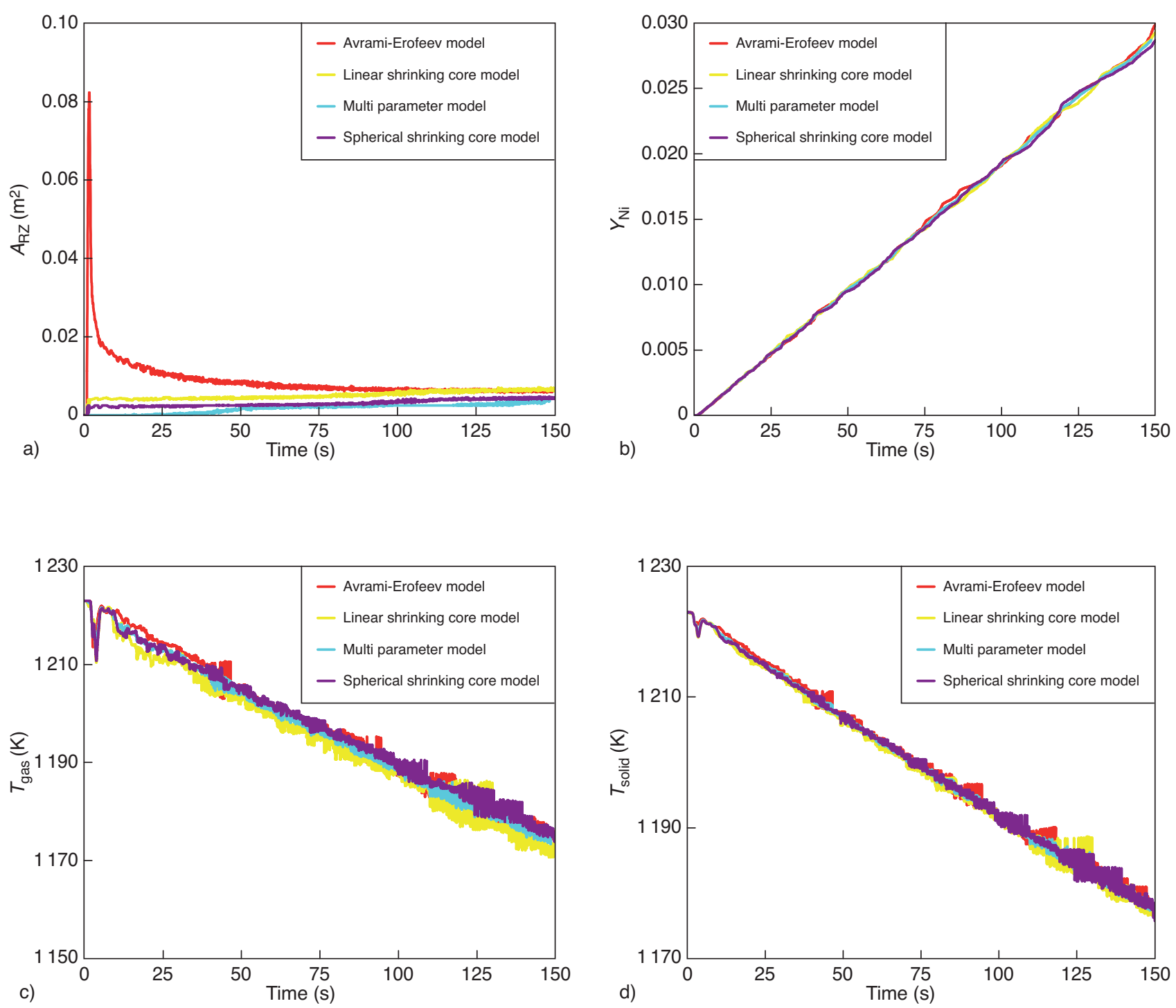

Figure 16

a) Area of the reaction zone, b) mass fraction of $\mathrm{Ni}$ in the solid phase, c) gas temperature at the outlet and d) temperature of the solid phase over time for $X_{0}=0$.

Whereas in the beginning the endothermic reaction results in a constant drop in the gas outlet temperature over time, the gas outlet temperature gets constant or slightly rising after the reaction comes to a halt. Taking a look at the Ni content in the solid phase in Figure 17d gives the impression that both the Avrami-Erofeev model and the multi parameter model leave the reaction halted abruptly. For the multi parameter model this is in clear agreement with the data on the kinetics shown in Figure 14. For the Avrami-Erofeev model the halt must be an effect of the strong decrease in reaction rate when approaching full degrees of conversion.

\section{CONCLUSIONS}

Due to the lack of investigations on the reaction modeling within fluidized systems used for chemical looping combustion three different oxygen carrier materials were investigated on a case by case basis. Four different kinetic models were considered whereas one was just proposed recently by Kruggel-Emden et al. [50]. For chemical looping combustion it is often assumed that gas/solid reactions of the carrier materials are sufficient fast [16], thereby leaving the kinetics and the selected kinetic model to have only minor 

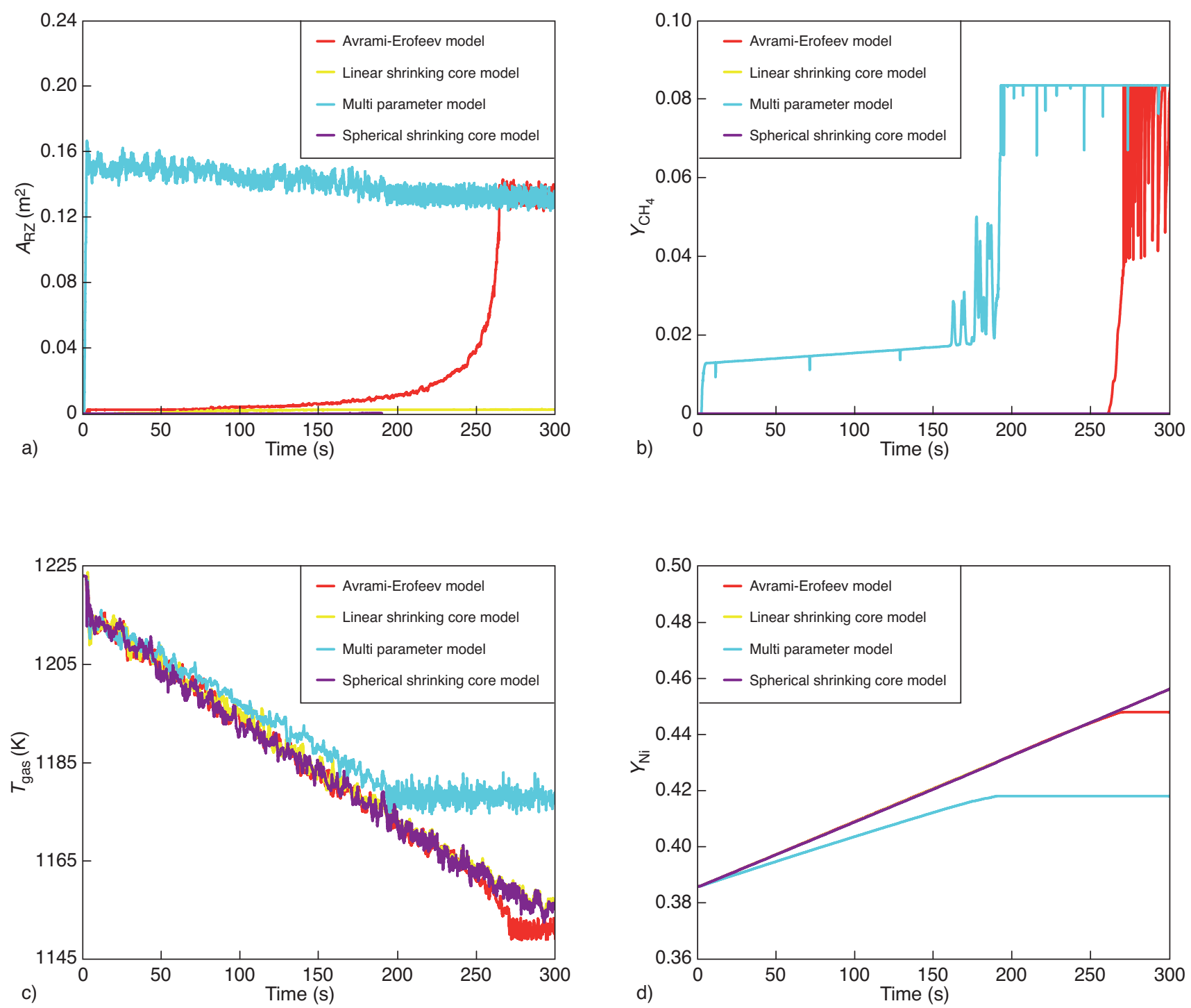

Figure 17

a) Area of the reaction zone, b) mass fraction of $\mathrm{Ni}$ in the solid phase, c) temperature of the gas mixture at the outlet and d) mass fraction of $\mathrm{CH}_{4}$ at the outlet over time for $X_{0}=0.8$.

impact on macroscopic quantities within reaction vessels. This statement is true for some of the studied cases here and probably the majority of applications in which chemical looping combustion vessels are normally operated where it is desirable to achieve full conversion of the fuel or oxygen. However in simulations which consider scale-up of equipment, changes in design or transient modes of operation like start-up or other operational changes the conversion of the gaseous reactants may be temporarily incomplete. In these cases small changes in the kinetic models and the kinetic modeling data may have a strong impact on the quantities linked to a chemical looping reaction vessel. Therefore here sophisticated models have to be applied to guarantee for a correct modeling.

The study performed reveals the limitations associated with the classical models like the Avrami-Erofeev, the linear shrinking core and the spherical shrinking core model. They are not applicable over the whole range of conversion a carrier particle may encounter. A solution may pose multi parameter models [50] which are able to represent the correct limits of the conversion processes. Still the number of experiments providing data that could be used to adjust kinetic 
models which could further be applied in multi phase CFD or particle oriented models is very limited. In particular, fuel gas mixtures lack detailed investigation. In general there is the strong need to perform more experimental investigations in order to get a better basis on which modeling can contribute to an enhancement of chemical looping combustion processes.

\section{ACKNOWLEDGMENTS}

The authors gratefully acknowledge the financial support by the Humboldt Foundation.

\section{REFERENCES}

1 IPCC Fourth Assessment Report, Paris, France (2007).

2 Herzog H., Eliasson B., Kaarstad O. (2000) Capturing greenhouse gases, Sci. Am. 282, 2, 72-79.

3 Yang H., Xu Z., Fan M., Gupta R., Slimane R.B., Bland A.E., Wright I. (2008) Progress in carbon dioxide separation and capture: A review, J. Environ. Sci. 20, 14-27.

4 Lyngfelt A., Lecker B. (1999) Technologies for $\mathrm{CO}_{2}$ Separation, Proceedings of the Minisymposium on $\mathrm{CO}_{2}$ Capture and Storage, Göteborg, Sweden.

5 Knoche K.F., Richter H. (1968) Verbesserung der Reversibilität von Verbrennungsprozessen, Brennst.-Wärme-Kraft 20, 205-210.

6 Richter H.J., Knoche K.F. (1983) Reversibility of combustion processes, Efficiency and Costing, Second Law Analysis of Processes, Gaggioli R.A. (ed), ACS Symp. Series 235, 71-85.

7 Lewis W.K., Gilliland E.R. (1954) Production of pure carbon dioxide, US Patent Nos. 2,665,971 and 2,665,972.

8 Ishida M., Zheng D., Akehata T. (1987) Evaluation of a Chemical-Looping-Combustion Power-Generation System by Graphic Exergy Analysis, Energy 12, 2, 147-154.

9 Ishida M., Jin H.G. (1994) A New Advanced Power-Generation System Using Chemical-Looping Combustion, Energy 19, 4, 415-422.

10 Hendriks C.A., Blok K., Turkenburg W.C. (1993) Promising Options to Remove Carbon Dioxide from Power Plants, Proceedings of the International Symposium on $\mathrm{CO}_{2}$ Fixation and Efficient Utilization of Energy, Tokyo, Japan.

11 Naqvi R., Wolf J., Bolland O. (2007) Part-load analysis of a Chemical-Looping Combustion (CLC) combined cycle with $\mathrm{CO}_{2}$ capture, Energy 32, 360-370.

12 Lyngfelt A., Leckner B., Mattisson T. (2001) A fluidized-bed combustion process with inherent $\mathrm{CO}_{2}$ separation; application of chemical-looping combustion, Chem. Eng. Sci. 56, 10, 31013113.

13 Son S.R., Kim S.D. (2006) Chemical-Looping Combustion with $\mathrm{NiO}$ and $\mathrm{Fe}_{2} \mathrm{O}_{3}$ in a Thermobalance and Circulating Fluidized Bed Reactor with Double Loops, Ind. Eng. Chem. Res. 45, 8, 2689-2696.

14 Gnanapragasam N.V., Reddy B.V., Rosen M.A. (2009) Hydrogen production from coal using coal direct chemical looping and syngas chemical looping combustion systems: Assessment of system operation and resource requirements, Int. J. Hydrogen Energ. 34, 2606-2615.
15 Fan L., Li F., Ramkumar S. (2008) Utilization of chemical looping strategy in coal gasification processes, Particuology 6, 131-142.

16 Noorman S., Annaland M.V., Kuipers H. (2007) Packed bed reactor technology for chemical-looping combustion, Ind. Eng. Chem. Res. 46, 12, 4212-4220.

17 Noorman S., Annaland M.V., Kuipers J.A.M. (2009) Experimental validation of packed bed chemical-looping combustion, Chem. Eng. Sci. (in press).

18 Kim B.S., Sohn H.Y. (2002) A novel cyclic reaction system involving $\mathrm{CaS}$ and $\mathrm{CaSO}_{4}$ for converting sulfur dioxide to elemental sulfur without generating secondary pollutants. 3 . Kinetics of the hydrogen reduction of the calcium sulfate powder to calcium sulfide, Ind. Eng. Chem. Res. 41, 13, 3092-3096.

19 Andrus H.E., Chiu J.H., Thibeault P.R., Brautsch A. (2009) Alstom's calcium oxide chemical looping combustion coal power technology development, Proceedings of the 34th Internaional Technical Conference on Clean Coal \& Fuel Systems, Clearwater, Florida, USA.

20 Hossaina M.M., de Lasa H.I. (2008) Chemical-looping combustion (CLC) for inherent $\mathrm{CO}_{2}$ separations - a review, Chem. Eng. Sci. 63, 18, 4433-4451.

21 Abad A., Mattisson T., Lyngfelt A., Ryden M. (2006) Chemicallooping combustion in a $300 \mathrm{~W}$ continuously operating reactor system using a manganese-based oxygen carrier, Fuel 85, 9, 1174-1185.

22 De Diego L.F., Garcia-Labiano F., Gayan P., Celaya J., Palacios J.M., Adanez J. (2007) Operation of a $10 \mathrm{kWth}$ chemical-looping combustor during $200 \mathrm{~h}$ with a $\mathrm{CuO}-\mathrm{Al}_{2} \mathrm{O}_{3}$ oxygen carrier, Fuel 86, 7-8, 1036-1045.

23 Berquerand N., Lyngfelt A. (2008) The use of petroleum coke as fuel in a $10 \mathrm{~kW}(\mathrm{th})$ chemical-looping combustor, Int. J. Greenhouse Gas Control 2, 2, 169-179.

24 Berguerand N., Lyngfelt A. (2008) Design and operation of a $10 \mathrm{~kW}(\mathrm{th})$ chemical-looping combustor for solid fuels - Testing with South African coal, Fuel 87, 12, 2713-2726.

25 Adanez J., Dueso C., de Diego L.F., Garcia-Labiano F., Gayan P., Abad A. (2009) Methane Combustion in a 500 W-th ChemicalLooping Combustion System Using an Impregnated Ni-Based Oxygen Carrier, Energ. Fuel. 23, 1, 130-142.

26 Kolbitsch P., Bolhar-Nordenkampf J., Proll T., Hofbauer H. (2009) Comparison of Two Ni-Based Oxygen Carriers for Chemical Looping Combustion of Natural Gas in $140 \mathrm{~kW}$ Continuous Looping Operation, Ind. Eng. Chem. Res. 48, 11, 5542-5547.

27 Epple B., Stroehle J. (2008) $\mathrm{CO}_{2}$ Capture based on carbonate and chemical looping, VGB Powertech 11, 85-88.

28 Li F., Fan L.S. (2008) Coal conversion processes - progress and challenges, Energ. Environ. Sci. 1, 248-267.

29 Simsek E., Brosch B., Wirtz S., Scherer V., Krüll F. (2009) Numerical Simulation of Grate Firing Systems using a Coupled CFD / Discrete Element Method (DEM), Powder Technol. 193, 266-273.

30 Kruggel-Emden H., Stepanek F., Munjiza A. (2009) Discrete element methods for large scale particle/fluid simulations, $A S M E$ Pressure Vessels \& Piping Conference, Prague, Czech Republic.

31 Ding J., Gidaspow D. (1990) A bubbling fluidization model using kinetic theory of granular flow, AIChE J. 32, 1, 523-538.

32 Patil D.J., Annaland M.V., Kuipers J.A.M. (2004) Critical comparison of hydrodynamic models for gas-solid fluidized bedspart I: Bubbling gas-solid fluidized beds operated with a jet, Chem. Eng. Sci.60, 1, 57-72.

33 Patil D.J., Annaland M.V., Kuipers J.A.M. (2004) Critical comparison of hydrodynamic models for gas-solid fluidized bedspart II: Freely bubbling gas-solid fluidized beds, Chem. Eng. Sci. 60, $1,73-84$. 
34 Enwald H., Almstedt A.E. (1999) Fluid dynamics of a pressurized fluidized bed: Comparison between numerical solutions from two-fluid models and experimental results, Chem. Eng. Sci. 54, 329-342.

35 Cooper S., Coronella C.J. (2005) CFD Simulation of particle mixing in a binary fluidized bed, Powder Technol. 151, 27-36.

36 Vaishali S., Roy S., Mills P.L. (2008) Hydrodynamic simulation of gas-solids downflow reactors, Chem. Eng. Sci. 63, 5107-5119.

37 Gryczka O., Heinrich S., Deen N.G., Annaland M.V., Kuipers J.A.M., Jacob M., Moerl L. (2009) Characterization and CFDmodeling of the hydrodynamics of a prismatic spouted bed apparatus, Chem. Eng. Sci. 64, 3352-3375.

38 Jung J.W., Gamwo I.K. (2008) Multiphase CFD-based models for chemical looping combustion process: Fuel reactor modeling, Powder Technol. 183, 3, 401-409.

39 Ryu H.J., Bae D.H., Han K.H., Lee S.Y., Jin G.T., Choi J.H. (2001) Oxidation and reduction characteristics of oxygen carrier particles and reaction kinetics by unreacted core model, Korean J. Chem. Eng. 18, 831-837.

40 Levenspiel O. (1998) Chemical Reaction Engineering, New York, John Wiley and Sons.

41 Syamlal M., Rogers W., O'Brien T.J. (1993) MFIX documentation theory guide, Technical Note, DOE/METC-94/1004, NTIS/DE94000087, U.S. Department of Energy, Office of Fossil Energy, Morgantown Energy Technology Center Morgantown, WV, National Technical Information Service, Springfield, VA.

42 Deng Z.Y., Xiao R., Jin B.S., Song Q.L., Huang H. (2008) Multiphase CFD Modeling for a Chemical Looping Combustion Process (Fuel Reactor), Chem. Eng. Technol. 31, 12, 1754-1766.

43 Deng Z.Y., Xiao R., Jin B.S., Song Q.L. (2009) Numerical simulation of chemical looping combustion process with $\mathrm{CaSO}_{4}$ oxygen carrier, Int. J. Greenhouse Gas Control 3, 4, 368-375.

44 Jin B.S., Xiao R., Deng Z.Y., Song Q.L. (2009) Computational Fluid Dynamics Modeling of Chemical Looping Combustion Process with Calcium Sulphate Oxygen Carrier, Int. J. Chem. Reactor Eng. 7, A19.
45 Xu M., Ellis N., Ryu H.J., Lim C.J. (2007) Modeling of an Interconnected Fluidized Bed Reactor for Chemical Looping Combustion, The 12th International Conference on Fluidization, Vancouver, Canada.

46 Bolhar-Nordenkampf J., Proll T., Kolbitsch P., Hofbauer H. (2009) Comprehensive Modeling Tool for Chemical Looping Based Processes, Chem. Eng. Technol. 32, 3, 410-417.

47 Kolbitsch P., Proll T., Hofbauer H. (2009) Modeling of a 120 $\mathrm{kW}$ chemical looping combustion reactor system using a Nibased oxygen carrier, Chem. Eng. Sci. 64, 1, 99-108.

48 Kruggel-Emden H., Rickelt S., Stepanek F., Munjiza A. (2010) Development and testing of an interconnected multiphase CFDmodel for chemical looping combustion, Chem. Eng. Sci. 65, 16, 4732-4745.

49 Gidaspow D. (1994) Multiphase Flow and Fluidization, Academic Press, San Diego.

50 Kruggel-Emden H., Stepanek F., Munjiza A. (2009) A comparative study of reaction models for chemical looping combustion, Comput. Chem. Eng. (submitted).

51 Zafar Q., Abad A., Mattisson T., Gevert B., Strand M. (2007) Reduction and oxidation kinetics of $\mathrm{Mn}_{3} \mathrm{O}_{4} / \mathrm{Mg}-\mathrm{ZrO}_{2}$ oxygen carrier particles for chemical-looping combustion, Chem. Eng. Sci. 62, 6556-6567.

52 Johansson M., Mattisson T., Lyngfelt A. (2006) Investigation of $\mathrm{Mn}_{3} \mathrm{O}_{4}$ with stabilized $\mathrm{ZrO}_{2}$ for chemical-looping combustion, Chem. Eng. Res. Des. 84, A9, 807-818.

53 Zafar Q., Abad A., Mattisson T., Gevert B. (2007) Reaction kinetics of freeze-granulated $\mathrm{NiO} / \mathrm{MgAl}_{2} \mathrm{O}_{4}$ oxygen carrier particles for chemical-looping combustion, Energ. Fuel. 21, 2, 610-618. or distributed for profit or commercial advantage and that copies bear this notice and the full citation on the first page. Copyrights for components of this work owned by others than IFP Energies nouvelles must be honored. Abstracting with credit is permitted. To copy otherwise, to republish, to post on servers, or to redistribute to lists, requires prior specific permission and/or a fee: Request permission from Information Mission, IFP Energies nouvelles, fax. +33147527096 , or revueogst@ifpen.fr. 